Review Article

\title{
Pathomechanisms of Oxidative Stress in Inflammatory Bowel Disease and Potential Antioxidant Therapies
}

\author{
Tian Tian, Ziling Wang, and Jinhua Zhang \\ College of Life Science and Bioengineering, Beijing Jiaotong University, Beijing 100044, China \\ Correspondence should be addressed to Jinhua Zhang; zhangjh@bjtu.edu.cn
}

Received 28 January 2017; Revised 22 May 2017; Accepted 31 May 2017; Published 28 June 2017

Academic Editor: Javier Egea

Copyright (c) 2017 Tian Tian et al. This is an open access article distributed under the Creative Commons Attribution License, which permits unrestricted use, distribution, and reproduction in any medium, provided the original work is properly cited.

\begin{abstract}
Inflammatory bowel disease (IBD) is a chronic gastrointestinal disease whose incidence has risen worldwide in recent years. Accumulating evidence shows that oxidative stress plays an essential role in the pathogenesis and progression of IBD. This review highlights the generation of reactive oxygen species (ROS) and antioxidant defense mechanisms in the gastrointestinal (GI) tract, the involvement of oxidative stress signaling in the initiation and progression of IBD and its relationships with genetic susceptibility and the mucosal immune response. In addition, potential therapeutic strategies for IBD that target oxidative stress signaling are reviewed and discussed. Though substantial progress has been made in understanding the role of oxidative stress in IBD in humans and experimental animals, the underlying mechanisms are still not well defined. Thus, further studies are needed to validate how oxidative stress signaling is involved in and contributes to the development of IBD.
\end{abstract}

\section{Introduction}

Inflammatory bowel disease (IBD) is an incurable chronic inflammatory intestinal disorder of the gastrointestinal (GI) tract that dramatically impacts quality of life. Crohn's disease (CD) and ulcerative colitis (UC) are the principal types of IBD. CD may occur in any region of the GI tract involving the ileum and colon in a discontinuous pattern by transmural inflammation, while UC affects only the colon and rectum continuously and is restricted to the mucosa [1]. In clinical situations, $\mathrm{CD}$ can be associated with intestinal granulomas, strictures and fistulas, whereas these are not found in UC. In the US, IBD is the second most common inflammatory disorder and mainly affects people 15-30 years of age [2]. The incidence and prevalence of IBD are increasing rapidly worldwide, and the situation in Asia is more severe than that in the West $[3,4]$. Thus, IBD is becoming a major global public health problem $[5,6]$. Although it is widely known that IBD is an inappropriate immune response to environmental changes and the intestinal microbiota in a genetically susceptible background, the underlying mechanisms remain elusive. Accumulating data from both experimental models and clinical studies indicate that oxidative stress signaling is involved in and contributes to the development of IBD through multiple levels of function. Oxidative stress leads to damages of the mucosal layer in the GI tract and bacterial invasion, which in turn stimulates the immune response and initiates IBD [7]. In this review, we provide an overview of recent studies on oxidative stress and its implications in IBD and the crosstalk between oxidative stress signaling and the host response in the GI tract. Moreover, the therapeutic strategies targeting redox balance and potential molecular mechanisms are also discussed.

Over the past two decades, the understanding of IBD pathomechanisms has progressed rapidly. However, the current IBD treatments are less than ideal because of their significant risks and side effects [8]. More thorough insights into the role of oxidative stress in IBD will absolutely shed light on how to improve IBD therapy, particularly with regard to a combination medication plan that includes the use of natural and synthetic antioxidant compounds. In this review, we sequentially discuss the following: the triggers of oxidative stress, the antioxidant defense system, and the pathomechanism by which oxidative stress together with 
susceptibility genes, epithelial cells, mucosal immune cells, the microbiota, and environmental factors causes IBD; oxidative stress-related signaling pathways; and future strategies for the development of new antioxidant therapies for IBD patients.

\section{Oxidative Stress Signaling in the Gastrointestinal Tract}

Oxygen metabolism, which is necessary for mammalian cell survival, produces reactive oxygen species (ROS). ROS primarily refer to free radicals such as superoxide $\left(\mathrm{O}_{2}{ }^{-}\right)$, hydroxyl radicals ( $\mathrm{HO} \cdot)$, peroxyl $\left(\mathrm{RO}_{2} \cdot\right)$, alcoxyl (RO-), and hydroperoxyl $\left(\mathrm{HO}_{2} \cdot\right)$; lipid hydroperoxides; and reactive nonradical compounds including singlet oxygen $\left(\mathrm{O}_{2}\right)$, hydrogen peroxide $\left(\mathrm{H}_{2} \mathrm{O}_{2}\right)$, hypochlorous acid $(\mathrm{HOCl})$, chloramines $(\mathrm{RNHCl})$, and ozone $\left(\mathrm{O}_{3}\right)$ [9]. Reactive nitrogen species (RNS) mainly consist of nitric oxide ( $\cdot \mathrm{NO})$, nitrogen dioxide $\left(\cdot \mathrm{NO}_{2}\right)$, nonradical compounds, peroxynitrite $\left(\mathrm{ONOO}^{-}\right)$, and dinitrogen trioxide $\left(\mathrm{N}_{2} \mathrm{O}_{3}\right)$. ROS and RNS are both predominant mediators responsible for the intracellular damages of carbohydrates, proteins, lipids, and nucleic acids and are highly reactive due to their unstable conditions with unpaired electrons. It has been reported that ROS and RNS upregulate the expression of genes involved in innate and adaptive immune responses in the GI tract $[10,11]$.

Endogenous ROS are principally produced in intracellular organelles, such as the endoplasmic reticulum, mitochondria, peroxisomes, and the nucleus as well as in the cytosol and extracellular matrix, and the mitochondrial electron transport chain is responsible for a large proportion of ROS generation $[12,13]$. Mitochondria are the central organelles in energy metabolism and are exposed to ROS. Excess ROS generation leads to lower ATP production, suppression of the intracellular electron transport chain, and DNA damage in mitochondria. If this situation continues, mitochondrial bioenergetics and homeostasis are affected, resulting in cell death $[14,15]$. Mitochondria are the primary targets of oxidative stress, though the underlying mechanism of how this leads to IBD has not yet been revealed.

Multiple enzymes, such as peroxidases, NADPH oxidase (NOX), xanthine oxidase (XO), lipoxygenases (LOXs), glucose oxidase, myeloperoxidase (MPO), nitric oxide synthase (NOS), and cyclooxygenases (COXs), participate in endogenous ROS generation by catalyzing chemical reactions $[16,17]$. Among these enzymes, mucosal NOXs, such as the NOX2 complex, NOX1, and dual oxidase 2 (DUOX2), have been reported as novel IBD risk factors, further demonstrating that an imbalance in redox homeostasis is critical for IBD pathogenesis [18]. XO mainly functions in the intestinal mucosa, generating ROS and leading to GI tract injuries [19], while MPO is active in inflamed mucosa in UC patients and contributes to the progression of malignancies [20]. NOS have contradictory effects, maintaining GI mucosal integrity as well as causing injuries in UC and peptic ulcers [21, 22]. COX-1 and COX-2 are both upregulated in human ulcers, while COX-2 is closely associated with precancerous alterations in the GI mucosa in colon inflammation and Helicobacter pylori-induced gastritis [23].
In addition, oxidative stress can also be activated by environmental factors, such as radiation, chemotherapy, cigarette smoking, luminal antigens, alcohol, drugs, and xenobiotics, all of which contribute to IBD [7]. Iron (Fe) and copper $(\mathrm{Cu})$ in the diet, trans-fatty acids in some types of processed food, and acrylamide in snacks and crackers all trigger oxidative stress by increasing ROS generation [24-26]. High concentrations of alcohol can directly impair the mucosal barrier of the GI tract. Beyond that, various drugs and xenobiotics have been reported to enhance the production of free radicals in the gut [27].

Under physiological conditions, the cell can tolerate a certain level of ROS due to its antioxidant capacity, which is critical for intestinal homeostasis. However, an excessive oxidant load resulting from increased ROS generation or decreased reduction reactions can overwhelmingly enhance membrane permeability, alter the inflammatory response, and result in lipid and protein modifications, DNA damage, apoptosis, and carcinogenesis [28-30]. This condition is known as oxidative stress, a prominent imbalance between the pro-oxidants and antioxidants observed in many human diseases, such as cancer, diabetes, cardiovascular diseases, atherosclerosis, and chronic obstructive pulmonary disease [31]. Oxidative stress has been implicated in autoimmune disorders (rheumatoid arthritis, systemic lupus erythematosus, psoriasis, and celiac disease) and neurodegenerative diseases (Alzheimer's disease, Parkinson's disease, amyotrophic lateral sclerosis, and multiple sclerosis) [31]. Oxidative stress has also been shown to specifically induce gastroduodenal ulcers [32], IBD [33] (the focus of our review), and even gastric and colorectal cancer [34].

\section{Antioxidant Defenses in the Gastrointestinal Tract}

Although uncontrolled oxidative stress is destructive to the GI tract, the body's antioxidant defenses can counteract the effects caused by excess ROS. These defense mechanisms ensure that the concentrations of ROS/RNS are under control and will not exert harmful effects. The endogenous antioxidant system mainly consists of intracellular enzymatic antioxidants, such as superoxide dismutases (SODs), glutathione peroxidase (GPX), and catalase (CAT); intracellular nonenzymatic antioxidant glutathione; and extracellular antioxidants including vitamins, minerals, ceruloplasmin, and uric acid.

3.1. Intracellular Enzymatic Antioxidants. SODs, metal ion cofactor-requiring enzymes, can catalyze the reduction of $\mathrm{O}_{2} \cdot{ }^{-}$into $\mathrm{O}_{2}$ and further into $\mathrm{H}_{2} \mathrm{O}_{2}$. Three SOD isoforms exist in mammalian cells: SOD1 (Cu/ZnSOD, cytosol), SOD2 (MnSOD, mitochondria), and SOD3 (Cu/ZnSOD, extracellular) [35]. As the major form of SODs, SOD1 accounts for almost $70 \%$ of the SODs in the cell and resides in the cytoplasm, where it catalyzes the dismutation of $\mathrm{O}_{2}{ }^{-}$ into $\mathrm{H}_{2} \mathrm{O}_{2}$, and SOD1 or catalase can subsequently remove uncharged $\mathrm{H}_{2} \mathrm{O}_{2}$ from the mitochondria into the cytosol. SOD2 protects the mitochondria from $\mathrm{O}_{2}{ }^{-}$and is essential for cell survival, as SOD2-null mice do not survive after birth 
[36]. SOD3 is prone to binding to glycosaminoglycans such as heparin [37]. Clinical data have demonstrated differential mucosal expression of three SOD isoforms in IBD patients: SOD2 expression was dramatically upregulated, while SOD1 was less affected, and SOD3 was decreased particularly in intestinal epithelial cells (IECs) [38]. SOD activity is associated with the disease course of IBD patients [39]. SOD activity induced by intrarectal acetic acid is also found higher in both UC and CD patients than in controls, and elevated SOD levels can be restored to normal when patients are in remission $[40,41]$. On the whole, the total activities of SODs are increased in IBD pathogenesis as a reaction to protect the tissue against oxidative damage under the condition of inflammation and oxidative stress in IBD. Consistent with this, SOD levels in the peripheral blood of IBD patients are already being used as a biomarker for oxidative stress.

GPX can catalyze glutathione into oxidized glutathione (glutathione disulfide (GSSG)) and reduce $\mathrm{H}_{2} \mathrm{O}_{2}$ into $\mathrm{H}_{2} \mathrm{O}$ or lipid hydroperoxides (ROOH) into stable alcohols. GPX, together with glutathione reductase (GSSG-R), maintains low glutathione (GSH) levels and protects the cell from peroxide damage. There are eight GPX isoforms in humans, and most of their active sites contain selenocysteine residues [42]. GPX2 is specifically expressed in the epithelium of the GI tract, while GPX1 is ubiquitously distributed. GPX2 plays a major role in defending against oxidative stress and inflammation in the intestinal mucosa in mouse models of UC and $\mathrm{CD}$ and has been reported to be induced in pathogenic conditions such as gastric cancer and IBD [42-44]. Increased GPX2 expression has also been shown in colitis, which is induced by signal transducers and activators of transcription (STAT) factors $[45,46]$. The combined mutations of GPX1 and GPX2 in mice result in symptoms resembling IBD due to oxidative damage and inflammation in the GI tract [47]. In addition, GPX3 secreted by IECs contributes to the extracellular antioxidant activities in the intestinal mucosa [48]. Actually, there are many controversial and conflicting reports in comparing the antioxidant capacities of SOD and GPX in IBD with their respective controls due to diverse experimental methods and conditions: therefore, additional researches are necessary.

CAT is mainly located in peroxisomes and catalyzes the reduction of $\mathrm{H}_{2} \mathrm{O}_{2}$ into $\mathrm{H}_{2} \mathrm{O}$ and $\mathrm{O}_{2}$ [49]. It is primarily distributed in the human liver, kidney, and erythrocytes. Altered CAT expression can be caused by a series of pathogens related to GI tract diseases, such as Escherichia coli, Shigella, Salmonella, Campylobacter jejuni [50], Helicobacter pylori [51], and H. hepaticus [52]. Decreased CAT activity has been reported in patients affected by $\mathrm{CD}$ [53], colorectal cancer [54], gastric adenocarcinoma, and H. pylori-positive stomach ulcers [55]. Experiments in genetically modified mice demonstrated that enhanced CAT activity is associated with reduced occurrence of colitis and colon cancer $[56,57]$.

3.2. Intracellular Nonenzymatic Antioxidants. Glutathione is a significant intracellular nonenzymatic antioxidant. Its reduced form, GSH, a more prevalent agent, is a soluble antioxidant that is highly expressed in the cytoplasm, nucleus, and mitochondria. GSH, together with three related enzymes, glutathione peroxidase (GPX), glutathione reductase (GSR), and glutathione S-transferases (GST), forms an antioxidant barrier in the gut mucosa. GSH has been utilized as a biomarker for both inflammation and oxidative stress. In some cases of inflammation, GSH consumption increased sharply [58], while in different IBD subtypes, the GSH level exhibited contradictory trends. Experimental colitis models normally show decreased GSH levels [59-61]. A lower GSH level has been observed in dextran sulfate sodium- (DSS-) induced colitis and can be restored to a normal level by antioxidants [47, 62].

Melatonin (MEL) is a strong antioxidant that is originally synthesized in the pineal gland in mammals. It can reduce oxidative stress in both lipid and aqueous cell environments by crossing physiological barriers, such as the mitochondria membrane [63, 64]. MEL scavenges peroxyl and hydroxyl radicals and plays a protective role in early and advanced stages of several diseases involving ROS metabolites including IBD [65-67]. We will discuss the detailed potential of MEL as a medication in the section on IBD therapies.

3.3. Extracellular Antioxidants. Vitamin A or $\beta$-carotene (pro-vitamin A) is found in yellow fruits and green vegetables and exhibits remarkable antioxidant activity that is dependent on retinol-binding proteins. Vitamin $\mathrm{C}$ synthesized from glucose can be obtained from fresh fruits and vegetables and can reduce various ROS. Vitamin E is reported to protect the cell membrane from lipid peroxidation. These vitamins are all antioxidants that have been reported to be insufficient in the blood of many UC or CD patients mostly due to the lack of fruits and vegetables in their diets [68-70].

Minerals including zinc $(\mathrm{Zn})$, copper $(\mathrm{Cu})$, manganese $(\mathrm{Mn})$, and iron $(\mathrm{Fe})$ are essential for some antioxidant enzymes. Different isoforms of SOD require $\mathrm{Zn}, \mathrm{Cu}$, or $\mathrm{Mn}$ as cofactors, and iron is needed for CAT activity [71]. Polyphenols are mainly obtained from plants. Flavonoids, important polyphenols, suppress XO and other ROSrelated enzymes, such as COX, LOX, GST, and NOX $[72,73]$. These extracellular antioxidants mainly exist in fruits and vegetables.

\section{Pathomechanisms of Oxidative Stress in IBD}

Although the mechanisms underlying the etiology of IBD have not been thoroughly illuminated, it is commonly accepted that numerous factors including genetic susceptibility, alterations in IECs, dysregulation of immune responses, intolerance to the microbiota, and environmental factors in a background of oxidative stress together contribute to IBD development.

4.1. Genetic Susceptibility in IBD and Oxidative Stress. In recent years, the genetic variations of IBD patients have been comprehensively investigated. With the rapid development of new high-throughput technologies and largescale collaborations worldwide, researchers have found 200 genetic risk loci associated with IBD, including NOD2/ CARD15, ATG16L1, IRGM, CARD9, RNF186, PRDM1, IL$23 R$, and $I L-10$ [74-76]. 
In addition to the reported disease-specific loci, UC and CD share some susceptibility genes, such as IR23, IL12B, NKX2-3, and MST1. The UC-specific risk loci are $I L-10$ and HLA, while the CD-specific ones are NOD2, ATG16L1, and IRGM1 [77-81]. In CD, NOD2/CARD15 is the most important locus, and it can affect the mucosal recognition of bacteria and contribute to the duration of nuclear factor kappa $B$ $(\mathrm{NF}-\kappa \mathrm{B})$ activation and inflammation [82]. Genome-wide association studies (GWAS) have also identified other genes that are functionally related to immunodeficiency, such as RIPK2, TNFSF15, IFNGR1/2, TYK2, and CARD9 [83-85]. Autophagy, which is activated to digest cellular organelles upon cell starvation or infection, has been recognized as a pathogenic mechanism of $\mathrm{CD}$. For instance, the variant T300A of ATG16L1 has been widely reported as a risk factor that functions in autophagy during CD-related intestinal inflammation $[75,86]$, which also facilitated the identification of susceptibility genes IRGM1, SMURF1, and ATG16L2 in CD [83, 87-89]. Mutations in NOD2 and ATGL16L1 have been found to contribute to morphological alterations in Paneth cells in CD patients [90]. In addition, NOD2, ATG16L1, and IRGM1 have been suggested to interact with each other [76]. Mutations in immunity-associated guanosine triphosphatase $M$ and leucine-rich repeat kinase 2, which are essential in autophagy, and variations in NLRP3 have been reported to be related to $C D$ [91-93]. Functional analyses of these susceptibility genes and their related pathways all highlighted the defective innate immunity present in CD. HLA class II genes, cadherin, laminin $\beta 1$, and MUC19 have been discovered to be associated with UC in a GWAS meta-analysis [81, 94]. Caucasian CD and UC populations shared the mutation D299G in Toll-like receptors 4 (TLR4) [95], while variants of IL-23R and IL-17A have been found in subsets of Korean UC and CD populations [96, 97]. Along with the IL-23R pathway, the susceptibility genes $I L-12 B$, $J A K 2$, and SATA3 have also been discovered in CD [98], whereas polymorphisms in $I L-22$ and $I L-10$ receptor 2 have been found, respectively, in UC patients and children with early-onset enterocolitis $[79,99]$. The functions of susceptibility loci identified by GWAS analyses have not been fully deciphered, and further detailed genetic studies are still needed. These susceptibility genes also explain why the family histories in both CD and UC patients and their relatives are more common.

Variations of antioxidant/biotransformation enzyme genes can alter the enzyme activity and contribute to the risk of IBD. For example, the polymorphisms $N A D(P) H$ :quinone oxidoreductase 1 (NQO1) C609T and SOD2 Ala-9Val are involved in the risk of UC and clinical responses to therapies [100]. Mutations of GST M1 or T1 are related to IBD progression, and the two combined will further increase the risk. UC patients with defective GST M1 activity in the whole blood exhibited early disease onset and more severe symptoms $[101,102]$. The paraoxonase (PON) gene located on chromosome 7q21.3-22.1 shows characteristics of a susceptibility gene in both UC and CD. In a case-control study, the elevated PON1 activity of the PON1 R192 allele protected against IBD development in a Jewish population from Israel [103]. In addition, a polymorphism in the promoter of
Nrf2, whose protein product regulates the expression of intestinal detoxifying and antioxidant genes and acts as a defender, has been associated with UC development in a Japanese population [104].

\subsection{Epithelial Cells of the Gut in IBD and Oxidative Stress.} The intestinal epithelium, which exhibits both organspecific and immune functions, has been recognized as playing a central role in the pathogenesis of IBD. Epithelial cells form a cell barrier lining the GI tract between the host and various organisms, which is essential for maintaining mucosal homeostasis. The barrier layer is maintained by tight junctions, adherens junctions, and desmosomes. Paneth cells, goblet cells, absorptive cells, and enteroendocrine cells are the four major secretory cell types in IEC populations [105], and Paneth cells play an essential role in controlling bacteria via the secretion of antimicrobial peptides [106]. IECs express pattern-recognition receptors (PRRs), such as TLRs, to distinguish commensal and invasive pathogenic bacteria, which are important for intestinal mucosal homeostasis [107, 108]. Once excessive ROS are generated in the gut, oxidative stress can accelerate cell damages by modifying the functions of proteins and causing lipid peroxidation [109]. During mucosal inflammation, IECs as well as neutrophils and macrophages produce superoxide and nitric oxide by activating NOX and inducible nitric oxide synthase (iNOS), respectively, both induced by inflammatory cytokines. IECs produce more ROS/RNS via NOX and iNOS activation. This ROS overload can damage cytoskeleton proteins and lead to alterations in tight junctions and epithelial permeability in IECs, finally resulting in barrier disruption $[110,111]$. In this way, oxidative stress inflames the GI tract, and IBD is initiated. During inflammation, bacteria can penetrate the epithelial barrier and activate PRR signaling at the endothelium, elevating TLRs and NOD expression on endothelial cells [112]. Endothelial cells also express CD40 and CD40L proteins, which belong to the tumor necrosis factor (TNF) receptor superfamily and can costimulate immune cells during inflammation [113]. All of the above demonstrate that the endothelium acts as a second barrier during inflammation. The microvasculature surrounding the epithelial cells can recruit inflammatory mediators, leading to further tissue damages and inflammation expansion. This inflammation finally causes mucosal injuries accompanied by alterations in IECs, such as goblet cell loss, crypt cell hyperplasia, reduced mucous production and ulcerations.

4.3. Mucosal Immune Cells in IBD and Oxidative Stress. In the GI tract, innate immunity consists of epithelial cells, neutrophils, macrophages, dendritic cells, and natural killer (NK) cells, while the adaptive immune system consists of $\mathrm{T}$ lymphocytes and B cells, which release cytokines and antibodies upon activation. The mucosal immune system can delicately distinguish pathogenic, nonpathogenic, and normal gut microorganisms via an efficient mechanism. Under normal conditions, the balance between proinflammatory (TNF- $\alpha$, IL-1, IL-6, IL-8, IL-17, and IL-23) and antiinflammatory (IL-5, IL-10, IL-11, and TGF- $\beta$ ) cytokines is tightly controlled in the GI mucosa. Neutrophils together 
with other cell types initiate inflammation by secreting proinflammatory cytokines to further activate the adaptive immune system [114]. Recently, it has been accepted that IECs also participate in the adaptive immune response [115].

Innate and adaptive immunity are both affected in IBD, while adaptive immunity can sustain inflammation in CD but not initiate it $[116,117]$. The immune mechanism underlying IBD pathogenesis is a disruption of the balance between $\mathrm{T}$ helper (Th) cells and regulatory $\mathrm{T}$ cells, particularly the intolerance of regulatory $\mathrm{T}$ cells. CD is reportedly characterized by Th1 cell-mediated inflammation with excess IL-12, IL-17, and IL-23 production, whereas UC is dominated by cytokines such as IL-4, IL-5, IL-10, and IL-13 produced by Th2-type $\mathrm{T}$ cells [76]. In $\mathrm{CD}$, the microbiota triggers the Th1 response, generating interferon- $\gamma$ and TNF- $\alpha$ and leading to the mucosal barrier damage [118]. The NF- $\kappa \mathrm{B}$ signaling pathway is activated not only in leukocytes but also in the mucosal IECs of CD patients [119]. In UC, NK cells generate Th2 cytokines, arousing the immune response, and IL-13 mainly leads to IEC apoptosis, which provides positive feedback to NK cells $[120,121]$. The activation of immune cells, mainly macrophages and neutrophils, can cause superoxide and nitric oxide generation by NOX and NOS and the production of the oxidant peroxynitrite, all of which are involved in the pathogenesis of IBD and the initiation and progression of CD in particular $[45,122,123]$. During inflammation, other immune cells, such as leukocytes and monocytes, can also augment ROS production during respiration, prostaglandin, and leukotriene metabolism, resulting in further tissue damage [124].

In mouse colitis models, the loss of macrophages or neutrophils decreases ROS/RNS production, reduces proinflammatory cytokine generation, and alleviates intestinal inflammation and damage [125]. The active neutrophils and macrophages as well as the IECs in the GI tract generate more ROS, which can be inferred by the level of 8-hydroxy2'-deoxyguanosine (8-OHdG) in the blood, a biomarker for oxidative damage in IBD patients [76]. The infiltration of inflammatory cells in the mucosal further damages the GI tissue, forming a vicious cycle.

4.4. Interaction between Oxidative Stress and the Microbiota in the GI Tract in IBD. The human gut microbiota includes the population of microorganisms, such as bacteria, viruses, and fungi that inhabit the GI tract. The microbiota is involved in several protective, structural, and metabolic functions and plays a pivotal role in gut homeostasis and host health. Microbiota restricts the proliferation of pathogenic bacteria in the GI tract, activates the immune system, regulates nutrient utilization and host metabolism [126, 127], and controls vitamin and enzyme production. The microbiota also produces short-chain fatty acids (SCFAs), ethanol, lactate, phenols, and succinate; degrades proteins and carbohydrates; and transforms bile acids [128]. In particular, SCFAs derived from bacteria fermentation, including butytrate, propionate, and acetate, are essential for mucosa homeostasis and anti-inflammatory interleukin production [129]. Previous evidence has demonstrated that the balance between the commensal microbiota in the GI tract and host mucosal immune responses plays a significant role in the pathogenesis and duration of IBD [130]. Several commensal microorganisms are suspected to function as potential pathogenic factors in the development of IBD, such as $E$. coli, Saccharomyces cerevisiae, and Mycobacterium avium paratuberculosis (MAP). In UC, mucosa-associated E. coli was found in $68 \%$ of patients compared with $6 \%$ of controls, suggesting that it plays a possible pathogenic role [131]. MAP has been investigated for its latent function in CD pathogenesis, which remains controversial [132-134]. Recently, in gut flora research, there has been an emerging trend of studying the entire composition and associated causality of all types of flora in IBD patients. Dysbiosis, the alteration of the commensal microorganism composition or the decreased complexity of the microbiota ecosystem, has been featured in UC and CD patients. IBD treatments also affect the microbiome [5, 135-137]. Thus, studies of the microbiome may inform the development of probiotic-based treatments for IBD in the future.

ROS induction plays a central role in microbiota-linked GI diseases, including IBD and colorectal cancer. ROS are associated with intestinal dysbiosis. During inflammation, the gut microbiota can generate ROS directly, which can also cause DNA damage in infected cells [138-140]. It has been reported that $H$. pylori can induce neutrophils to produce ROS while generating ROS itself, contributing to gastric carcinogenesis [141]. The situation is similar to that in IBD. Gut microorganisms can accelerate NO and NOS production by the host via macrophage activation in response to inflammation inducing DNA damage. Some specific bacteria can produce NOS [142]. Oxidative stress is caused by an imbalance in pro-oxidative molecules and antioxidant defenses, leading to cellular impairments, including DNA damage, protein aggregation, and membrane dysfunction. Upon bacterial infection, the DNA repair system is altered by bacteria modulation. It has been reported that some enteropathogenic $E$. coli strains can affect the DNA mismatch repair (MMR) system by secreting effector proteins in HT-29 cells in vitro. Thus, the accumulation of mutations due to defects in the MMR system can induce inflammation-associated carcinogenesis $[143,144]$. Oxidative stress caused by ROS generation stimulates an initial inflammatory response via positive feedback and leads to additional ROS production and further tissue damage [69]. Obviously, more studies are needed to further elucidate the underlying mechanisms involved in the interactions between the gut microbiota composition and oxidative stress in IBD development.

4.5. Environmental Factors in IBD and Oxidative Stress. Environmental factors such as sanitary issues, high consumption of saturated fats and refined sugar, frequent use of antibiotics, and even social stress are all suspected to contribute to a high risk of IBD [145]. These factors may be more accurately categorized as lifestyle factors $[6,132,146,147]$. Here, we mainly focus on two environmental factors in IBD and their association with oxidative stress: smoking and wine consumption. Smoking is the most significant environmental factor for CD risk according to epidemiological data, whereas it positively affects the process of UC development. The 
underlying mechanism of its dual roles in CD and UC has not yet been clarified [148]. Among more than 4500 chemical components in tobacco smoke, nicotine, carbon monoxide (CO), and NO are the main active modulators that function in the intestinal immune system and are involved in IBD pathogenesis [149]. Several studies have explored the effects of smoking in animal models through exposure to nicotine or other tobacco smoke via oral administration or injection of these ingredients. One area of research focuses on the effects of tobacco smoke on inflammatory cells and mediators, while another concentrates on the intestinal epithelium and mucosal layer. Above all, cigarette smoke can interact with oxidative stress in IBD development. First, in addition to influencing ROS-generation pathways, cigarette smoke also contains a high concentration of ROS in its gas and tar. Second, metal ions in tobacco smoke can facilitate the transformation of hydrogen peroxide into the highly reactive hydroxyl radical [150]. It has been reported that iNOS activity is increased and oxidative stress is elevated in the small intestine after nicotine administration. Cigarette smoke exposure dramatically inactivates SOD in the colon, while the GSH level remains stable, indicating a reduced capacity to remove free radicals in the colon [151-153]. These findings demonstrate that smoke can sensitize the gut to oxidative stress and promote the IBD process.

Wine consumption is another environmental factor that is pervasive in daily life, though its effects on IBD remain controversial. The beneficial aspects of wine are mainly attributed to its most abundant nonalcoholic components, the phenolic compounds, which can protect the intestinal mucosa from oxidative stress as antioxidants [154]. The polyphenols in wine can be digested by IECs or consumed by the gut bacteria, which is important for their bioactivities. These compounds act as scavengers of free radicals or interfere with inflammatory molecules during IBD $[155,156]$. The other effects of wine on IBD come from the alcohol, which can lead to prolonged oxidative stress and inflammation, especially at high concentrations. Alcohol can cause mucosal damage directly and even elevate the risk of colorectal cancer [157, 158]. Thus, it is essential to distinguish among the different components in wine and clarify their interactions with oxidative stress in IBD. Generally, moderate wine consumption is recommended for inactive IBD patients as well as healthy people.

\subsection{Redox Signaling Pathways Involved in IBD}

4.6.1. NF- $\kappa B$ Signaling Pathway. NF- $\kappa \mathrm{B}$ is a significant regulator in multiple pathogenic processes and is aberrantly activated in IBD $[119,159,160]$. NF- $\kappa$ B can modulate the permeability of the intestinal layer and is associated with IEC homeostasis [161], while chronic NF- $\kappa$ B signaling may also intensify the chronic intestinal inflammation observed in the mucosa of UC and CD patients [119, 159]. Microbial-activated TLRs and TNF- $\alpha$ recognized by IECs stimulate downstream NF- $\kappa \mathrm{B}$ signaling events, which are also sensitive to oxidative stress. TNF- $\alpha$ facilitates superoxide generation in colon cells via the activation of NOX1 and NADPH oxidase organizer 1 (NOXO1) [162]. NOX activation, ROS generation, LC8 peptide release, and $\mathrm{I} \kappa \mathrm{B} \alpha$ phosphorylation are all involved in the activation of $\mathrm{NF}-\kappa \mathrm{B}$ by TNF $\alpha$ [163]. Studies in DSS-induced murine models have demonstrated that phenyl-N-tert-butylnitrone, an antioxidant drug that suppresses NF- $\kappa \mathrm{B}$, can alleviate inflammation symptoms. This finding also proves that oxidative stress contributes to the activation of NF- $\kappa$ B signaling in IBD [164].

$\mathrm{NF}-\kappa \mathrm{B}$ activation can elevate the transcription of five types of genes that are pivotal in IBD pathogenesis: first, proinflammatory cytokines including IL-6, IL-8, IL-16, and TNF- $\alpha$; second, genes modulating cell survival and propagation, such as the p53-upregulated modulator of apoptosis (PUMA), whose upregulation by NF- $\kappa$ B causes epithelial cell apoptosis and contributes to UC development [165]; third, genes associated with the permeability of the intestinal barrier, for instance, the myosin light chain kinase (MYLK), which is upregulated by TNF- $\alpha$-induced NF- $\kappa \mathrm{B}$ activation and leads to the degradation of myosin in the intestinal barrier [165]; fourth, metalloproteinases, which can digest mucosal cells and are also triggered by TNF- $\alpha$; and fifth, enzymes including COX- 2 and iNOS, which activate NF- $\kappa \mathrm{B}$ and interfere with barrier stability via ROS metabolism [159].

4.6.2. Nuclear Factor-Erythroid 2-Related Factor 2 Signaling Pathway. Nuclear factor-erythroid 2-related factor 2 (Nrf2) is a key transcription factor that can maintain mucosa homeostasis by suppressing excessive ROS generation in IBD. Nrf2 negatively regulates the proinflammatory response and mucosal impairment via an antioxidant mechanism. Nrf2-KO mice demonstrated more severe symptoms with a substantial loss of crypts compared with those of wild-type mice in a DSS-induced colitis model. Furthermore, Nrf2$\mathrm{KO}$ mice showed increased expressions of proinflammatory genes, including $I L-1 \beta, I L-6, I L-8, i N O S$, and $C O X-2$, and decreased expression of antioxidant enzymes, such as hemeoxygenase-1 and GST Mu-1 [166, 167]. The gene immediate early response-3 (IER3) negatively modulates Nrf2 activation through the phosphatidylinositol 3 kinase/ protein kinase B (PI3K/Akt) pathway. A lack of IER3 stimulates Akt and Nrf2 and results in reduced ROS production and apoptosis in a colitis model [168]. Thus, Nrf2 is kept at a low level in IBD because of activated IER3 in the mucosa.

With regard to oxidative stress, Nrf2 has been reported to suppress protein kinase $\mathrm{C}$ and decrease NOX activation by increasing the level of the antioxidants GSH, which also explains why ROS levels and production are decreased in Nrf2-KO mice [169]. Moreover, upon NOX1 activation, cholesterol oxidation products, oxysterols, contribute to free radical driven-apoptosis and induce the cytokines IL- $1 \beta$, IL-6, IL-8, and IL-23 and monocyte chemotactic protein-1 (MCP-1) as well as TLR2 and TLR9. In this way, oxysterols promote mucosal barrier damage in IBD $[170,171]$.

As discussed in previous sections, intracellular enzymatic antioxidants such as MnSOD, Cu/ZnSOD, GPX, and CAT are upregulated in the mucosa of $\mathrm{UC}$ and $\mathrm{CD}$ patients $[38,44,172]$. In a mouse model of severe acute colitis, overexpression of $\mathrm{Cu} / \mathrm{ZnSOD}$ decreased mortality but had no protective effects on chronic inflammation of the GI tract [173]. A murine colitis model showed that Gpx2 is 
upregulated via signal transducer and activator of transcription (STAT) not Rrf2 [46]. In addition, spontaneous ileocolitis developed in Gpx1 and Gpx2 double knockout mice due to Nox 1 overexpression and excessive ROS production $[47,174$, 175]. Experimental results in vitro indicate that GPX2 inhibits COX-2 expression and membrane-associated prostaglandin synthase-1 (mPGES-1) in the intestine while detaching prostaglandin E2 (PGE2) [176].

Furthermore, oxidative stress will cause DNA damage primarily in the mitochondria. The instability of mitochondrial DNA contributes to increased susceptibility to colorectal cancer transformed from UC [12, 177]. Conversely, treatments with antioxidant ubiquinone that targets mitochondria, MitoQ, can decrease mitochondrial ROS and relieve the symptoms of colitis in a DSS-induced mouse model [178]. Mitochondria are regarded as significant cellular drivers and mediators of the inflammatory process [179]. The roles of mitochondria in oxidative stress require further exploration, which may lead to a better understanding of IBD initiation and progression.

\section{New Therapies Targeting Oxidative Stress in IBD}

IBD is a typical intestinal disorder that involves dysfunctions in immune response. The leading ideology of IBD treatments mainly focuses on reducing inflammation. In traditional therapeutic approaches, anti-inflammatory agents, such as sulfasalazine, mesalazine, infliximab, and corticosteroids, are utilized to antagonize inflammation and promptly relieve IBD symptoms. These agents exert their functions by blocking TNF- $\alpha$ - or NF- $\kappa \mathrm{B}$-mediated inflammation. Nevertheless, these anti-inflammatory agents often cause side effects, such as Gl problems, anemia, and hypersensitivity, when taken for the prolonged treatments of IBD and may result in drug intolerance. Immune modulators, such as thiopurines and cyclosporine, are alternative choices that can be used to treat IBD via immunosuppression $[118,180]$. These drugs are commonly used together with anti-inflammatory agents, though immune modulators can have cytotoxic effects that may enhance other diseases or infections. Some of these drugs have direct free radical-scavenging capabilities, while others have indirect antioxidant functions via TNF- $\alpha$.

Thus, the use of these drugs must be carefully monitored as part of a personalized medication plan [181, 182].

As the incidence and severity of IBD and colorectal cancer have increased, demands have grown for revolutionary therapeutic approaches for IBD. Because the pathomechanism of oxidative stress in IBD has been suggested by many laboratory reports and clinical trials, regulating Nrf2 signaling and suppressing ROS generation by targeting NOX or mitochondria are both potential treatment options for IBD. Furthermore, some nonconventional therapeutic methods with antioxidant effects, such as ROS generation inhibitors, hormones, functional dietary interventions, and natural or synthetic substances that inhibit cell death and activate antioxidant enzymes, have attracted increasing attentions as complementary and alternative medicines (CAMs) for IBD $[183,184]$. These antioxidant therapies may have fewer side effects, lower costs, and better treatment responses, offering new hopes to IBD patients, especially those with UC in both the active phase and the remission stage of the disease [185]. As we discussed above in the antioxidant defense section, intracellular or extracellular enzymatic or nonenzymatic antioxidants could be developed into potential medications for IBD.

5.1. Inhibitors against ROS Generation. Drugs that have antioxidant effects primarily include COX-2 inhibitors, angiotensin II type 1 inhibitors, and hydroxymethylglutaryl CoA reductase inhibitors. Molecules that can block the activity of enzymes (such as COX-2 inhibitors) have been reported to reduce endogenous ROS generation and inflammatory responses in IBD patients [186]. Among the candidate angiotensin II type 1 blockers, telmisartan (TLM) has both antiinflammatory and antioxidant characteristics and exhibits protection in the treatment of colitis. It has been reported that oral TLM administration inhibits ROS production by suppressing NF- $\kappa \mathrm{B}, \mathrm{COX} 2$, and iNOS expression in a rat model of colitis. In addition, TLM can suppress lipid peroxidation, remove NO', and increase GSH levels and SOD, GPX activities in this model, all of which contribute to oxidative stress reduction [187]. Inhibitors of hydroxymethylglutaryl CoA reductases are often referred to as statins, such as simvastatin and rosuvastatin, which attenuate oxidative stress by inhibiting MPO activity, decreasing lipid peroxidation, and increasing SOD activity, as reported in a rat model [188].

5.2. Hormones. MEL has been successfully tested as a nontraditional hormonal therapy for IBD. Generally, MEL functions directly on the GI tract in an endocrine, paracrine, or autocrine manner to influence the epithelium and regulate the gut environments [189]. Several experimental and clinical reports have verified the protective roles of MEL as an inflammation regulator, as discussed in the antioxidant defense section of this review. MEL acts as a specific antioxidant that scavenges free radicals, leading to decreased oxidative damages in either lipid or aqueous cellular environments during both the initial and advanced phases of IBD $[65,190]$. MEL also acts as an antioxidant indirectly by modulating antioxidant enzymes, such as SOD and GPX [191, 192]. It has multiple potential targets such as Nrf2, STAT3, IL-17, sirtuins, poly (ADP-ribose) polymerase 1 (PARP1), and death proteins and is involved in telomere dysfunction and epigenetic alterations: these functions could be used to design novel strategies to alleviate the symptoms of UC. The dose and administration time of MEL are key factors in the treatments of UC patients [193]. In addition, MEL suppresses autophagy induced by ROS and sirtuins, both of which correlate with the circadian clock machinery and might contribute to antitumorigenesis in the colon [194]. MEL metabolism is altered in UC patients and is associated with disease severity, indicating that MEL supplementation may help relieve symptoms in UC patients [195]. MEL also regulates the intestinal immune system in colitis models. It could be introduced as a supplemental medication in IBD treatments, though its side effects over the long term have not been determined. 
Additional clinical trials are still needed to determine the antioxidant effects of MEL.

5.3. Synthetic Substances. N-acetylcysteine (NAC) is a synthetic substance that provides cysteine for GSH synthesis and can increase the antioxidant defense activity, showing benefits in both animal model experiments and clinical tests in IBD patients [196, 197]. NAC can scavenge the free radicals and metals involved in ROS generation and the inflammatory responses [198]. Moreover, NAC inhibits $\mathrm{NF}-\kappa \mathrm{B}$, and its antioxidant effects contribute to the recovery of IBD [199]. In mouse IBD models, oral treatments with NAC for one and a half months led to decreased lipid and protein oxidation, increased GSH and CAT activities, and improved antioxidant status in the colon, demonstrating that long-term oral administration may be more beneficial for patients [200].

Modified SOD and propionyl-L-carnitine (PLC) have also been applied in clinical trials because of their strong treatment effects in IBD $[201,202]$. Intravenous administration of a lecithinized human $\mathrm{Cu} / \mathrm{ZnSOD}$ (PC-SOD) was found to suppress MPO and NF- $\kappa \mathrm{B}$ activity. PC-SOD also exhibited benefits and safety when administered to UC patients for 14 days [203, 204]. In addition, a recombinant SOD (rec-SOD) elevated antioxidant activity and reduced ROS damage as well as MPO activity in the colon of a mouse colitis model [202]. PLC, an antioxidant molecule, can suppress ROS generation and remove free radicals leading to symptom relief in UC patients in phase II clinical trials $[205,206]$. Further studies are needed to determine the optimal safe dose of PLC and the effects of its long-term use.

5.4. Polyphenols and Other Herbal Plant Extracts. Polyphenols are a class of over 7000 compounds that are abundant in dietary fruits and vegetables with high fiber content. Polyphenols have antioxidant, anti-inflammatory, immunomodulatory, and apoptotic characteristics and can regulate several target genes involved in inflammation, such as NF$\kappa \mathrm{B}$, Nrf-2, STAT, and mitogen-activated protein kinases (MAPKs). Polyphenols also inhibit the generation of cytokines, such as IL- 8 , IL- $1 \beta$, and TNF- $\alpha$, and promote the activities of intracellular antioxidants including SOD and GPX. Through their antioxidant activities, polyphenols directly scavenge free radicals and interrupt some redox signaling pathways, such as the NF- $\kappa \mathrm{B}$ and MAPK pathways $[156,207]$. In addition, polyphenols protect the intestinal mucosal by reducing intestinal permeability via tight junction stabilization. They also enhance the healthy microbiota in the gut and the production of SCFAs similar to probiotics [208]. A systematic review of epidemiological observations showed that a lower risk of both CD and UC is associated with a high intake of fruits and vegetables. Clinical trials of IBD interventions have demonstrated that $22 \mathrm{CD}$ patients who followed a semi-vegetarian diet rich in polyphenols for over 2 years reported symptom relief [209]. Another study from a murine colitis model showed that polyphenols can decrease the harmful effects of ROS on the intestinal mucosa. However, attention should be paid to the following negative effects of polyphenols: first, they may act as pro-oxidants at high doses; second, they may affect the absorption of other drugs; and third, they may interfere with metabolism pathways.

Polyphenols can be classified as flavonoids (such as isoflavonoids and anthocyanins) and nonflavonoids (such as phenolic acids, coumarins, stilbenes, and tannins). Flavonoids have been reported to protect the cell against oxidative stress and preserve the epithelial mucosa layer of the gut in vivo and in vitro [210]. Resveratrol from grapes, berries and peanuts, curcumin from Curcuma longa, quercetin from Quercus species, catechin from green tea, and proanthocyanidins from grape seeds and berries all represent polyphenols with antioxidant capabilities. Anthocyanins are an important subset of flavonoids and are ubiquitously distributed in many berries, such as strawberries, blueberries, cranberries, blackberries, and sunrouge buds. Anthocyanins play therapeutic and protective roles in the management of IBD by inducing anti-inflammatory cytokines, modulating TLR4, and improving the intestinal microbiota [211]. Another polyphenol, curcumin, a yellow agent derived from turmeric, has long been used in traditional medicines to treat inflammation and chronic diseases [212, 213]. Curcumin can reportedly scavenge free radicals and decrease oxidative stress and inflammation via the Nrf2 signaling pathway or can act as a TNF blocker in vivo and in vitro [214-216]. In a rat model, oral administration of curcumin alleviated colon damage and decreased inflammation and apoptosis [217]. Several clinical studies have reported the benefits of curcumin in IBD patients without serious side effects [218-221]. Therefore, curcumin is a promising drug for IBD treatments.

There are also other antioxidant substances extracted from natural plants or herbal medicines that may be useful in the design of IBD medications. To date, 55 herbal or plant products have been studied in various IBD models, including thyme, lemongrass, ginger extract, Panax notoginseng, and guggulsterone, some of which have long been utilized in Chinese or Indian traditional medicine for IBD treatments [222]. However, some of these compounds may also exhibit toxicity problems due to their pro-oxidative properties, leading to liver and renal damage [223]. Thus, further trials of herbal extracts in animal models are indispensable. So far, no herbal extracts from plants have been certified as adjuvant medications in IBD by the International Society of Nutritional Therapy [224, 225].

5.5. Functional Dietary and Antioxidant Micronutrients. Functional foods for IBD therapy may include food in a diet, such as camel's milk, or an ingredient added to a diet, such as extra virgin olive oil (EVOO). Camel's milk is rich in many minerals ( $\mathrm{Ca}, \mathrm{Fe}, \mathrm{Mg}, \mathrm{Cu}$, and $\mathrm{Zn}$ ), vitamins (A, B2, C, and $\mathrm{E})$, insulin, and lactoferrin, with excellent antioxidant and anti-inflammatory effects, and it is deficient in sugar, protein, and fat. It has been used as a nutritional supplement for immune-deficient patients and may become a valuable replenishment for IBD patients [226]. EVOO consumption can activate antioxidant enzymes such as CAT, SOD, and GPX and regulate immune responses against oxidative stress to relieve IBD symptoms [227]. EVOO is widely reported to 
protect against colon cancer, which is a later stage of IBD progression [228].

Moreover, many types of nutrients are found to act as antioxidants in IBD, such as glutathione; vitamins A, C, and E; carotenoids; free metals such as selenium (Se), $\mathrm{Cu}$, and $\mathrm{Zn}$; nutritional lipids such as polyunsaturated fatty acids (PUFAs); bioactive peptides; and amino acids [68].

Micronutrients include vitamin $\mathrm{C}$, vitamin $\mathrm{E}$, and some minerals, as discussed in the extracellular antioxidant defense section of this review. Vitamin E is lipid-soluble and active in membranes and has been used as a supplement in UC treatments. In addition, minerals such as $\mathrm{Zn}$ and Se are essential factors for the antioxidant enzymes SOD and GPX. It has been reported that combined treatments with $\mathrm{Zn}$ and vitamin $\mathrm{E}$ achieved better effects on redox balance than either treatment alone in a rat model [229].

Carotenoids, which exist in plants, algae, and microbiota, act against oxidative damage, protecting the cell and preventing heavy metal accumulation in the body. Humans and animals can only acquire carotenoids from their diets and cannot manufacture them by themselves. Astaxanthin and fucoxanthin are two major carotenoids in marine animals and plants that exert strong antioxidant effects by scavenging free radicals [230].

Se is essential for the catalytic activity of GSH peroxidase, and Se deficiency directly leads to GSH defects and higher oxidative stress. In clinical trials, Se deficiency and selenoprotein inactivation in $\mathrm{CD}$ and UC patients have been associated with disease severity [231]. Se-deficient mice subjected to DSS-induced epithelial injuries show increased tumorigenesis and progression after AOM/DSS treatment [232]. These findings indicate the significance of selenoprotein as potent antioxidants.

Of the PUFAs, omega-3 fatty acids are the most efficient in attenuating inflammation in IBD. Omega- 3 fatty acids can be derived from different resources, such as nuts, fish, and linseed. These fatty acids are healthy and can reduce weight loss, decrease inflammation, promote membrane homeostasis, and improve the body's peripheral neural system. Omega-3 fatty acids are also substrates for resolvin, maresin, and protectin synthesis and may interfere with IBD progression by reducing oxidative stress and decreasing the expression of TNF- $\alpha$ and inflammatory cytokines. Many clinical and animal experiments have been conducted to explore the benefits of omega- 3 fatty acids in IBD. However, their effects remain controversial due to the various forms of omega-3 fatty acids, varied responses to diverse genetic receptors, and differences in methodology. More valid data regarding omega-3 fatty acids are required to determine their clinical applications in IBD [233].

In addition, bioactive peptides and amino acids have been demonstrated to attenuate intestine inflammation, reduce oxidative stress, and recover mucosal homeostasis in IBD models, suggesting another alternative dietary therapy for IBD [234].

5.6. Probiotics. Probiotics, living microorganisms that can benefit the host, have attracted increasing research interests in recent years. Probiotics that enhance antioxidant defenses are involved in ROS removal, enzyme inhibition, metal chelation, and antioxidant enzyme synthesis. Some research reports have demonstrated that probiotics can increase SOD, CAT, and GPX activities and GSH levels while decreasing MPO and NO activities [56, 235].

The most commonly used probiotics are strains of Lactobacillus and Bifidobacterium, which are reported to secrete enzymes such as SOD and metal-chelating as well as antioxidant molecules such as exopolysaccharides to protect the intestine from IBD or colorectal cancer in rat models [236, 237]. Lactobacillus fermentum ME-3 has been reported to improve total antioxidant activity (TAA) and total antioxidant status (TAS) in healthy volunteers demonstrating its probiotic functions against oxidative stress [238]. E. coli Nissle 1917, VSL\#3 (a food supplement that contains 8 different strains of live lactic acid bacteria), Lactobacilli, and Bifidobacteria have anti-inflammatory effects and relieve clinical symptoms in UC patients [239]. It has been summarized that the distinctions of disease subtypes, disease location, and medication possibilities as well as the bacterial strains and applied doses should be assessed in future studies to evaluate the use of probiotics in IBD treatments [240].

\section{Discussion and Future Perspectives}

In the current review, we have summarized the current knowledge on oxidative stress in IBD. Increased ROS generation and decreased antioxidant activities contribute to the major pathogenesis and progression of IBD. The GI tract epithelium is continuously exposed to multiple stimuli, such as ingested food, resident microbiota or other infections, gastric acid, and other pro-oxidants [241-244]. During inflammation, immune cells, such as leukocytes, monocytes, and neutrophils augment ROS production during respiratory, prostaglandin, and leukotriene metabolism, resulting in further tissue damages [124]. Several literature reports have found ROS/RNS upregulation in IBD patients $[11,69]$ as well as in murine colitis models [187, 235, 245]. A significant correlation between oxidative stress and IBD severity has been implied [246]. In addition to overwhelming ROS generation, the defective antioxidant defense is another key factor promoting IBD progression. When antioxidant defenses fail, oxidative stress occurs, which further leads to IBD initiation. In the setting of IBD, downregulation of CAT, GPX, and SOD has been demonstrated in human colonic mucosa, submucosa, and serosa compared with expression in the small intestine. In addition, an overall reduction of nonenzymatic antioxidants such as vitamins, $\beta$-carotene, tocopherol, and glutathione has been found in IBD patients, and the extent of reduction correlates with the severity of IBD [70, 247-249]. However, with regard to antioxidant levels in clinical trials and animal models of IBD, different studies have demonstrated controversial or even contradictory results possibly due to the use of different animal models, diverse methods, and varied biomarkers. Thus, more precise experimental and clinical studies should be performed to provide further insights into IBD.

Oxidative stress is now regarded as a potential pathogenic and critical factor in the initiation, progression, and severity 
of IBD, rather than a consequence of chronic inflammation in the intestinal mucosa. Nevertheless, the underlying mechanisms are still far from thoroughly elucidated. Based on the laboratory reports and clinical trials, increasing numbers of antioxidants, such as ROS generation inhibitors, hormones, synthetic substances, polyphenols and herbal plant extracts, functional foods, micronutrients, and probiotics, are potential therapeutic substances that target oxidative stress in IBD. However, further studies are needed to confirm the exact effects of these promising drugs and the suitable doses and administration routes. A combination of new antioxidant-enhancing therapies and conventional medications may achieve better curative effects in IBD and should be explored in future clinical trials.

\section{Conflicts of Interest}

The authors declare that there is no conflict of interests regarding the publication of this paper.

\section{Acknowledgments}

This review was supported by the Fundamental Research Fund for the Central Universities (2015JBM094 and 2015JBM095) and Grants 31301022 and 81541051 from the National Natural Science Foundation of China.

\section{References}

[1] D. Corridoni, K. O. Arseneau, and F. Cominelli, "Inflammatory bowel disease," Immunology Letters, vol. 161, no. 2, pp. 231-235, 2014.

[2] E. V. Loftus Jr. and W. J. Sandborn, "Epidemiology of inflammatory bowel disease," Gastroenterology Clinics of North America, vol. 31, no. 1, pp. 1-20, 2002.

[3] S. C. Ng, W. Tang, J. Y. Ching et al., "Incidence and phenotype of inflammatory bowel disease based on results from the Asia-Pacific Crohn's and colitis epidemiology study," Gastroenterology, vol. 145, no. 1, pp. 158-165, 2013, e152.

[4] Z. Zeng, Z. Zhu, Y. Yang et al., "Incidence and clinical characteristics of inflammatory bowel disease in a developed region of Guangdong Province, China: a prospective population-based study," Journal of Gastroenterology and Hepatology, vol. 28, no. 7, pp. 1148-1153, 2013.

[5] C. Huttenhower, A. D. Kostic, and R. J. Xavier, "Inflammatory bowel disease as a model for translating the microbiome," Immunity, vol. 40, no. 6, pp. 843-854, 2014.

[6] N. A. Molodecky, I. S. Soon, D. M. Rabi et al., "Increasing incidence and prevalence of the inflammatory bowel diseases with time, based on systematic review," Gastroenterology, vol. 142, no. 1, pp. 46-54, 2012, e42; quiz e30.

[7] P. Goyette, C. Labbe, T. T. Trinh, R. J. Xavier, and J. D. Rioux, "Molecular pathogenesis of inflammatory bowel disease: genotypes, phenotypes and personalized medicine," Annals of Medicine, vol. 39, no. 3, pp. 177-199, 2007.

[8] A. Dahan, G. L. Amidon, and E. M. Zimmermann, "Drug targeting strategies for the treatment of inflammatory bowel disease: a mechanistic update," Expert Review of Clinical Immunology, vol. 6, no. 4, pp. 543-550, 2010.
[9] K. Bedard and K. H. Krause, "The NOX family of ROSgenerating NADPH oxidases: physiology and pathophysiology," Physiological Reviews, vol. 87, no. 1, pp. 245-313, 2007.

[10] M. A. Alzoghaibi, "Concepts of oxidative stress and antioxidant defense in Crohn's disease," World Journal of Gastroenterology, vol. 19, no. 39, pp. 6540-6547, 2013.

[11] J. Pravda, "Radical induction theory of ulcerative colitis," World Journal of Gastroenterology, vol. 11, no. 16, pp. 2371-2384, 2005.

[12] E. A. Novak and K. P. Mollen, "Mitochondrial dysfunction in inflammatory bowel disease," Frontiers in Cell and Development Biology, vol. 3, p. 62, 2015.

[13] R. O. Poyton, P. R. Castello, K. A. Ball, D. K. Woo, and N. Pan, "Mitochondria and hypoxic signaling: a new view," Annals of the New York Academy of Sciences, vol. 1177, pp. 48-56, 2009.

[14] Y. Chen and S. B. Gibson, "Is mitochondrial generation of reactive oxygen species a trigger for autophagy?" Autophagy, vol. 4, no. 2, pp. 246-248, 2008.

[15] R. Scherz-Shouval and Z. Elazar, "ROS, mitochondria and the regulation of autophagy," Trends in Cell Biology, vol. 17, no. 9, pp. 422-427, 2007.

[16] A. C. Kulkarni, P. Kuppusamy, and N. Parinandi, "Oxygen, the lead actor in the pathophysiologic drama: enactment of the trinity of normoxia, hypoxia, and hyperoxia in disease and therapy," Antioxidants \& Redox Signaling, vol. 9, no. 10, pp. 1717-1730, 2007.

[17] E. J. Swindle and D. D. Metcalfe, "The role of reactive oxygen species and nitric oxide in mast cell-dependent inflammatory processes," Immunological Reviews, vol. 217, pp. 186-205, 2007.

[18] S. O'Neill, J. Brault, M. J. Stasia, and U. G. Knaus, "Genetic disorders coupled to ROS deficiency," Redox Biology, vol. 6, pp. 135-156, 2015.

[19] M. Sasaki and T. Joh, "Oxidative stress and ischemiareperfusion injury in gastrointestinal tract and antioxidant, protective agents," Journal of Clinical Biochemistry and Nutrition, vol. 40, no. 1, pp. 1-12, 2007.

[20] T. A. Ullman and S. H. Itzkowitz, "Intestinal inflammation and cancer," Gastroenterology, vol. 140, no. 6, pp. 18071816, 2011.

[21] M. D. Barrachina, J. Panes, and J. V. Esplugues, "Role of nitric oxide in gastrointestinal inflammatory and ulcerative diseases: perspective for drugs development," Current Pharmaceutical Design, vol. 7, no. 1, pp. 31-48, 2001.

[22] D. Rachmilewitz, F. Karmeli, R. Eliakim et al., "Enhanced gastric nitric oxide synthase activity in duodenal ulcer patients," Gut, vol. 35, no. 10, pp. 1394-1397, 1994.

[23] P. C. Konturek, J. Kania, G. Burnat, E. G. Hahn, and S. J. Konturek, "Prostaglandins as mediators of COX-2 derived carcinogenesis in gastrointestinal tract," Journal of Physiology and Pharmacology, vol. 56, Supplement 5, pp. 57-73, 2005.

[24] E. Bergmark, C. J. Calleman, F. He, and L. G. Costa, "Determination of hemoglobin adducts in humans occupationally exposed to acrylamide," Toxicology and Applied Pharmacology, vol. 120, no. 1, pp. 45-54, 1993.

[25] C. G. Fraga and P. I. Oteiza, "Iron toxicity and antioxidant nutrients," Toxicology, vol. 180, no. 1, pp. 23-32, 2002.

[26] D. Zapolska-Downar, A. Kosmider, and M. Naruszewicz, "Trans fatty acids induce apoptosis in human endothelial 
cells," Journal of Physiology and Pharmacology, vol. 56, no. 4, pp. 611-625, 2005.

[27] A. Bhattacharyya, R. Chattopadhyay, S. Mitra, and S. E. Crowe, "Oxidative stress: an essential factor in the pathogenesis of gastrointestinal mucosal diseases," Physiological Reviews, vol. 94, no. 2, pp. 329-354, 2014.

[28] L. A. Ridnour, J. S. Isenberg, M. G. Espey, D. D. Thomas, D. D. Roberts, and D. A. Wink, "Nitric oxide regulates angiogenesis through a functional switch involving thrombospondin-1," Proceedings of the National Academy of Sciences of the United States of America, vol. 102, no. 37, pp. 13147-13152, 2005.

[29] M. Valko, D. Leibfritz, J. Moncol, M. T. Cronin, M. Mazur, and J. Telser, "Free radicals and antioxidants in normal physiological functions and human disease," The International Journal of Biochemistry \& Cell Biology, vol. 39, no. 1, pp. 44-84, 2007.

[30] M. Valko, H. Morris, M. Mazur, P. Rapta, and R. F. Bilton, "Oxygen free radical generating mechanisms in the colon: do the semiquinones of vitamin K play a role in the aetiology of colon cancer?" Biochimica et Biophysica Acta, vol. 1527, no. 3, pp. 161-166, 2001.

[31] V. Chiurchiu and M. Maccarrone, "Chronic inflammatory disorders and their redox control: from molecular mechanisms to therapeutic opportunities," Antioxidants \& Redox Signaling, vol. 15, no. 9, pp. 2605-2641, 2011.

[32] Y. C. Peng, C. L. Hsu, C. F. Tung et al., "Chemiluminescence assay of mucosal reactive oxygen species in gastric cancer, ulcer and antral mucosa," Hepato-Gastroenterology, vol. 55, no. 82-83, pp. 770-773, 2008.

[33] M. B. Grisham, "Oxidants and free radicals in inflammatory bowel disease,” Lancet, vol. 344, no. 8926, pp. 859-861, 1994.

[34] T. Inokuma, M. Haraguchi, F. Fujita, Y. Tajima, and T. Kanematsu, "Oxidative stress and tumor progression in colorectal cancer," Hepato-Gastroenterology, vol. 56, no. 90, pp. 343-347, 2009.

[35] I. Fridovich, "Superoxide anion radical (O2-.), superoxide dismutases, and related matters," The Journal of Biological Chemistry, vol. 272, no. 30, pp. 18515-18517, 1997.

[36] Y. Li, T. T. Huang, E. J. Carlson et al., "Dilated cardiomyopathy and neonatal lethality in mutant mice lacking manganese superoxide dismutase," Nature Genetics, vol. 11, no. 4, pp. 376-381, 1995.

[37] S. L. Marklund, "Human copper-containing superoxide dismutase of high molecular weight," Proceedings of the National Academy of Sciences of the United States of America, vol. 79, no. 24, pp. 7634-7638, 1982.

[38] L. Kruidenier, I. Kuiper, W. van Duijn et al., "Differential mucosal expression of three superoxide dismutase isoforms in inflammatory bowel disease," The Journal of Pathology, vol. 201, no. 1, pp. 7-16, 2003.

[39] Y. Naito, T. Yoshikawa, T. Ando et al., "Changes in superoxide dismutase activity in the gastric mucosa of peptic ulcer patients," Journal of Clinical Gastroenterology, vol. 14, Supplement 1, pp. S131-S134, 1992.

[40] B. Beltran, P. Nos, F. Dasi et al., "Mitochondrial dysfunction, persistent oxidative damage, and catalase inhibition in immune cells of naive and treated Crohn's disease," Inflammatory Bowel Diseases, vol. 16, no. 1, pp. 76-86, 2010.

[41] K. M. Sakthivel and C. Guruvayoorappan, "Protective effect of Acacia ferruginea against ulcerative colitis via modulating inflammatory mediators, cytokine profile and NF-kappaB signal transduction pathways," Journal of Environmental Pathology, Toxicology and Oncology, vol. 33, no. 2, pp. 8398, 2014.

[42] R. Dayer, B. B. Fischer, R. I. Eggen, and S. D. Lemaire, "The peroxiredoxin and glutathione peroxidase families in Chlamydomonas reinhardtii," Genetics, vol. 179, no. 1, pp. 41-57, 2008.

[43] F. F. Chu, R. S. Esworthy, and J. H. Doroshow, "Role of Sedependent glutathione peroxidases in gastrointestinal inflammation and cancer," Free Radical Biology \& Medicine, vol. 36, no. 12, pp. 1481-1495, 2004.

[44] A. A. Te Velde, I. Pronk, F. de Kort, and P. C. Stokkers, "Glutathione peroxidase 2 and aquaporin 8 as new markers for colonic inflammation in experimental colitis and inflammatory bowel diseases: an important role for $\mathrm{H} 2 \mathrm{O} 2$ ?" European Journal of Gastroenterology \& Hepatology, vol. 20, no. 6, pp. 555-560, 2008.

[45] A. Mangerich, P. C. Dedon, J. G. Fox, S. R. Tannenbaum, and G. N. Wogan, "Chemistry meets biology in colitis-associated carcinogenesis," Free Radical Research, vol. 47, no. 11, pp. 958-986, 2013.

[46] F. Hiller, K. Besselt, S. Deubel, R. Brigelius-Flohé, and A. P. Kipp, "GPx2 induction is mediated through STAT transcription factors during acute colitis," Inflammatory Bowel Diseases, vol. 21, no. 9, pp. 2078-2089, 2015.

[47] R. S. Esworthy, R. Aranda, M. G. Martin, J. H. Doroshow, S. W. Binder, and F. F. Chu, "Mice with combined disruption of Gpx1 and Gpx2 genes have colitis," American Journal of Physiology. Gastrointestinal and Liver Physiology, vol. 281, no. 3, pp. G848-G855, 2001.

[48] D. M. Tham, J. C. Whitin, K. K. Kim, S. X. Zhu, and H. J. Cohen, "Expression of extracellular glutathione peroxidase in human and mouse gastrointestinal tract," The American Journal of Physiology, vol. 275, no. 6, Part 1, pp. G1463-G1471, 1998.

[49] M. Schrader and H. D. Fahimi, "Peroxisomes and oxidative stress," Biochimica et Biophysica Acta, vol. 1763, no. 12, pp. 1755-1766, 2006.

[50] J. M. Atack and D. J. Kelly, "Oxidative stress in Campylobacter jejuni: responses, resistance and regulation," Future Microbiology, vol. 4, no. 6, pp. 677-690, 2009.

[51] M. Mori, H. Suzuki, M. Suzuki, A. Kai, S. Miura, and H. Ishii, "Catalase and superoxide dismutase secreted from Helicobacter pylori," Helicobacter, vol. 2, no. 2, pp. 100-105, 1997.

[52] J. G. Fox, F. E. Dewhirst, J. G. Tully et al., "Helicobacter hepaticus sp. nov., a microaerophilic bacterium isolated from livers and intestinal mucosal scrapings from mice," Journal of Clinical Microbiology, vol. 32, no. 5, pp. 1238-1245, 1994.

[53] M. Iborra, I. Moret, F. Rausell et al., "Role of oxidative stress and antioxidant enzymes in Crohn's disease," Biochemical Society Transactions, vol. 39, no. 4, pp. 1102-1106, 2011.

[54] D. Chang, Z. L. Hu, L. Zhang et al., "Association of catalase genotype with oxidative stress in the predication of colorectal cancer: modification by epidemiological factors," Biomedical and Environmental Sciences, vol. 25, no. 2, pp. 156-162, 2012.

[55] M. Monari, J. Foschi, C. Calabrese et al., "Implications of antioxidant enzymes in human gastric neoplasms," International Journal of Molecular Medicine, vol. 24, no. 5, pp. 693-700, 2009. 
[56] J. G. LeBlanc, S. del Carmen, A. Miyoshi et al., "Use of superoxide dismutase and catalase producing lactic acid bacteria in TNBS induced Crohn's disease in mice," Journal of Biotechnology, vol. 151, no. 3, pp. 287-293, 2011.

[57] A. de Moreno de LeBlanc, J. G. LeBlanc, G. Perdigon et al., "Oral administration of a catalase-producing Lactococcus lactis can prevent a chemically induced colon cancer in mice," Journal of Medical Microbiology, vol. 57, Part 1, pp. 100-105, 2008.

[58] A. G. Hall, "Review: the role of glutathione in the regulation of apoptosis," European Journal of Clinical Investigation, vol. 29, no. 3, pp. 238-245, 1999.

[59] V. Prabhu and C. Guruvayoorappan, "Protective effect of marine mangrove Rhizophora apiculata on acetic acid induced experimental colitis by regulating anti-oxidant enzymes, inflammatory mediators and nuclear factor-kappa B subunits," International Immunopharmacology, vol. 18, no. 1, pp. 124-134, 2014.

[60] E. A. Socca, A. Luiz-Ferreira, F. M. de Faria et al., "Inhibition of tumor necrosis factor-alpha and cyclooxigenase- 2 by Isatin: a molecular mechanism of protection against TNBSinduced colitis in rats," Chemico-Biological Interactions, vol. 209, pp. 48-55, 2014.

[61] C. L. Rise, V. V. Prabhu, and C. Guruvayoorappan, "Effect of marine mangrove Avicennia marina (Forssk.) Vierh against acetic acid-induced ulcerative colitis in experimental mice," Journal of Environmental Pathology, Toxicology and Oncology, vol. 31, no. 2, pp. 179-192, 2012.

[62] H. S. Oz, T. S. Chen, C. J. McClain, and W. J. de Villiers, "Antioxidants as novel therapy in a murine model of colitis," The Journal of Nutritional Biochemistry, vol. 16, no. 5, pp. 297-304, 2005.

[63] R. J. Reiter, "Melatonin: lowering the high price of free radicals," News in Physiological Sciences, vol. 15, pp. 246250, 2000.

[64] R. J. Reiter, S. D. Paredes, L. C. Manchester, and D. X. Tan, "Reducing oxidative/nitrosative stress: a newlydiscovered genre for melatonin," Critical Reviews in Biochemistry and Molecular Biology, vol. 44, no. 4, pp. 175-200, 2009.

[65] D. Bonnefont-Rousselot and F. Collin, "Melatonin: action as antioxidant and potential applications in human disease and aging," Toxicology, vol. 278, no. 1, pp. 55-67, 2010.

[66] A. Dominguez-Rodriguez, P. Abreu-Gonzalez, J. J. SanchezSanchez, J. C. Kaski, and R. J. Reiter, "Melatonin and circadian biology in human cardiovascular disease," Journal of Pineal Research, vol. 49, no. 1, pp. 14-22, 2010.

[67] R. E. Rosenstein, S. R. Pandi-Perumal, V. Srinivasan, D. W. Spence, G. M. Brown, and D. P. Cardinali, "Melatonin as a therapeutic tool in ophthalmology: implications for glaucoma and uveitis," Journal of Pineal Research, vol. 49, no. 1, pp. 1-13, 2010.

[68] O. Ioannidis, I. Varnalidis, G. Paraskevas, and D. Botsios, "Nutritional modulation of the inflammatory bowel response," Digestion, vol. 84, no. 2, pp. 89-101, 2011.

[69] A. Rezaie, R. D. Parker, and M. Abdollahi, "Oxidative stress and pathogenesis of inflammatory bowel disease: an epiphenomenon or the cause?" Digestive Diseases and Sciences, vol. 52, no. 9, pp. 2015-2021, 2007.

[70] S. Hengstermann, L. Valentini, L. Schaper et al., "Altered status of antioxidant vitamins and fatty acids in patients with inactive inflammatory bowel disease," Clinical Nutrition, vol. 27 , no. 4, pp. 571-578, 2008.

[71] E. D. Harris, "Regulation of antioxidant enzymes," The FASEB Journal, vol. 6, no. 9, pp. 2675-2683, 1992.

[72] J. E. Brown, H. Khodr, R. C. Hider, and C. A. Rice-Evans, "Structural dependence of flavonoid interactions with $\mathrm{Cu} 2+$ ions: implications for their antioxidant properties," The Biochemical Journal, vol. 330, Part 3, pp. 1173-1178, 1998.

[73] Y. Hanasaki, S. Ogawa, and S. Fukui, "The correlation between active oxygens scavenging and antioxidative effects of flavonoids," Free Radical Biology \& Medicine, vol. 16, no. 6, pp. 845-850, 1994.

[74] R. H. Duerr, K. D. Taylor, S. R. Brant et al., "A genome-wide association study identifies IL23R as an inflammatory bowel disease gene," Science, vol. 314, no. 5804, pp. 1461-1463, 2006.

[75] J. Hampe, A. Franke, P. Rosenstiel et al., “A genome-wide association scan of nonsynonymous SNPs identifies a susceptibility variant for Crohn disease in ATG16L1," Nature Genetics, vol. 39, no. 2, pp. 207-211, 2007.

[76] W. T. Uniken Venema, M. D. Voskuil, G. Dijkstra, R. K. Weersma, and E. A. Festen, "The genetic background of inflammatory bowel disease: from correlation to causality," The Journal of Pathology, vol. 241, no. 2, pp. 146-158, 2017.

[77] A. Franke, T. Balschun, T. H. Karlsen et al., "Sequence variants in IL10, ARPC2 and multiple other loci contribute to ulcerative colitis susceptibility," Nature Genetics, vol. 40, no. 11, pp. 1319-1323, 2008.

[78] S. A. Fisher, M. Tremelling, C. A. Anderson et al., "Genetic determinants of ulcerative colitis include the ECM1 locus and five loci implicated in Crohn's disease," Nature Genetics, vol. 40, no. 6, pp. 710-712, 2008.

[79] M. S. Silverberg, J. H. Cho, J. D. Rioux et al., "Ulcerative colitis-risk loci on chromosomes 1p36 and 12q15 found by genome-wide association study," Nature Genetics, vol. 41, no. 2, pp. 216-220, 2009.

[80] E. A. Festen, P. C. Stokkers, C. C. van Diemen et al., "Genetic analysis in a Dutch study sample identifies more ulcerative colitis susceptibility loci and shows their additive role in disease risk," The American Journal of Gastroenterology, vol. 105, no. 2, pp. 395-402, 2010.

[81] C. A. Anderson, G. Boucher, C. W. Lees et al., "Meta-analysis identifies 29 additional ulcerative colitis risk loci, increasing the number of confirmed associations to 47," Nature Genetics, vol. 43, no. 3, pp. 246-252, 2011.

[82] Y. Ogura, D. K. Bonen, N. Inohara et al., "A frameshift mutation in NOD2 associated with susceptibility to Crohn's disease," Nature, vol. 411, no. 6837, pp. 603-606, 2001.

[83] L. Jostins, S. Ripke, R. K. Weersma et al., "Host-microbe interactions have shaped the genetic architecture of inflammatory bowel disease," Nature, vol. 491, no. 7422, pp. 119124, 2012.

[84] K. Yamazaki, D. McGovern, J. Ragoussis et al., "Single nucleotide polymorphisms in TNFSF15 confer susceptibility to Crohn's disease," Human Molecular Genetics, vol. 14, no. 22, pp. 3499-3506, 2005.

[85] A. Franke, D. P. McGovern, J. C. Barrett et al., "Genome-wide meta-analysis increases to 71 the number of confirmed Crohn's disease susceptibility loci," Nature Genetics, vol. 42, no. 12, pp. 1118-1125, 2010. 
[86] J. D. Rioux, R. J. Xavier, K. D. Taylor et al., "Genome-wide association study identifies new susceptibility loci for Crohn disease and implicates autophagy in disease pathogenesis," Nature Genetics, vol. 39, no. 5, pp. 596-604, 2007.

[87] M. Parkes, J. C. Barrett, N. J. Prescott et al., "Sequence variants in the autophagy gene IRGM and multiple other replicating loci contribute to Crohn's disease susceptibility," Nature Genetics, vol. 39, no. 7, pp. 830-832, 2007.

[88] A. Orvedahl, R. Sumpter Jr., G. Xiao et al., "Image-based genome-wide siRNA screen identifies selective autophagy factors," Nature, vol. 480, no. 7375, pp. 113-117, 2011.

[89] S. K. Yang, M. Hong, W. Zhao et al., "Genome-wide association study of Crohn's disease in Koreans revealed three new susceptibility loci and common attributes of genetic susceptibility across ethnic populations," Gut, vol. 63 , no. 1, pp. 8087, 2014.

[90] K. L. VanDussen, T. C. Liu, D. Li et al., "Genetic variants synthesize to produce paneth cell phenotypes that define subtypes of Crohn's disease," Gastroenterology, vol. 146, no. 1, pp. 200-209, 2014.

[91] S. A. McCarroll, A. Huett, P. Kuballa et al., "Deletion polymorphism upstream of IRGM associated with altered IRGM expression and Crohn's disease," Nature Genetics, vol. 40, no. 9, pp. 1107-1112, 2008.

[92] Y. Tong, H. Yamaguchi, E. Giaime et al., "Loss of leucine-rich repeat kinase 2 causes impairment of protein degradation pathways, accumulation of alpha-synuclein, and apoptotic cell death in aged mice," Proceedings of the National Academy of Sciences of the United States of America, vol. 107, no. 21, pp. 9879-9884, 2010.

[93] A. C. Villani, M. Lemire, G. Fortin et al., "Common variants in the NLRP3 region contribute to Crohn's disease susceptibility," Nature Genetics, vol. 41, no. 1, pp. 71-76, 2009.

[94] D. P. McGovern, A. Gardet, L. Torkvist et al., "Genome-wide association identifies multiple ulcerative colitis susceptibility loci," Nature Genetics, vol. 42, no. 4, pp. 332-337, 2010.

[95] D. Franchimont, S. Vermeire, H. El Housni et al., "Deficient host-bacteria interactions in inflammatory bowel disease? The toll-like receptor (TLR)-4 Asp299gly polymorphism is associated with Crohn's disease and ulcerative colitis," Gut, vol. 53, no. 7, pp. 987-992, 2004.

[96] S. W. Kim, E. S. Kim, C. M. Moon et al., "Genetic polymorphisms of IL-23R and IL-17A and novel insights into their associations with inflammatory bowel disease," Gut, vol. 60, no. 11, pp. 1527-1536, 2011.

[97] Y. Li, Q. Mao, L. Shen et al., "Interleukin-23 receptor genetic polymorphisms and Crohn's disease susceptibility: a metaanalysis," Inflammation Research, vol. 59, no. 8, pp. 607$614,2010$.

[98] K. Wang, H. Zhang, S. Kugathasan et al., "Diverse genomewide association studies associate the IL12/IL23 pathway with Crohn disease," American Journal of Human Genetics, vol. 84, no. 3, pp. 399-405, 2009.

[99] E. O. Glocker, D. Kotlarz, K. Boztug et al., "Inflammatory bowel disease and mutations affecting the interleukin-10 receptor," The New England Journal of Medicine, vol. 361, no. 21, pp. 2033-2045, 2009.

[100] T. Kosaka, J. Yoshino, K. Inui et al., "Involvement of $\mathrm{NAD}(\mathrm{P}) \mathrm{H}$ :quinone oxidoreductase 1 and superoxide dismutase polymorphisms in ulcerative colitis," DNA and Cell Biology, vol. 28, no. 12, pp. 625-631, 2009.
[101] R. D. Mittal, P. K. Manchanda, H. K. Bid, and U. C. Ghoshal, "Analysis of polymorphisms of tumor necrosis factor-alpha and polymorphic xenobiotic metabolizing enzymes in inflammatory bowel disease: study from northern India," Journal of Gastroenterology and Hepatology, vol. 22, no. 6, pp. 920-924, 2007.

[102] E. Hertervig, A. Nilsson, and J. Seidegard, “The expression of glutathione transferase mu in patients with inflammatory bowel disease," Scandinavian Journal of Gastroenterology, vol. 29, no. 8, pp. 729-735, 1994.

[103] A. Karban, C. Hartman, R. Eliakim et al., "Paraoxonase (PON)1 192R allele carriage is associated with reduced risk of inflammatory bowel disease," Digestive Diseases and Sciences, vol. 52, no. 10, pp. 2707-2715, 2007.

[104] T. Arisawa, T. Tahara, T. Shibata et al., "Nrf2 gene promoter polymorphism is associated with ulcerative colitis in a Japanese population," Hepato-Gastroenterology, vol. 55, no. 82-83, pp. 394-397, 2008.

[105] J. Beisner, E. F. Stange, and J. Wehkamp, "Innate antimicrobial immunity in inflammatory bowel diseases," Expert Review of Clinical Immunology, vol. 6, no. 5, pp. 809-818, 2010.

[106] W. S. Garrett, J. I. Gordon, and L. H. Glimcher, "Homeostasis and inflammation in the intestine," Cell, vol. 140, no. 6, pp. 859-870, 2010.

[107] M. Fukata and M. Arditi, "The role of pattern recognition receptors in intestinal inflammation," Mucosal Immunology, vol. 6, no. 3, pp. 451-463, 2013.

[108] L. Pastorelli, C. De Salvo, J. R. Mercado, M. Vecchi, and T. T. Pizarro, "Central role of the gut epithelial barrier in the pathogenesis of chronic intestinal inflammation: lessons learned from animal models and human genetics," Frontiers in Immunology, vol. 4, p. 280, 2013.

[109] J. K. Andersen, “Oxidative stress in neurodegeneration: cause or consequence?" Nature Medicine, vol. 10, Supplement, pp. S18-S25, 2004.

[110] A. Banan, S. Choudhary, Y. Zhang, J. Z. Fields, and A. Keshavarzian, "Ethanol-induced barrier dysfunction and its prevention by growth factors in human intestinal monolayers: evidence for oxidative and cytoskeletal mechanisms," The Journal of Pharmacology and Experimental Therapeutics, vol. 291, no. 3, pp. 1075-1085, 1999.

[111] R. Rao, R. D. Baker, and S. S. Baker, "Inhibition of oxidantinduced barrier disruption and protein tyrosine phosphorylation in Caco-2 cell monolayers by epidermal growth factor," Biochemical Pharmacology, vol. 57, no. 6, pp. 685-695, 1999.

[112] J. Heidemann, W. Domschke, T. Kucharzik, and C. Maaser, "Intestinal microvascular endothelium and innate immunity in inflammatory bowel disease: a second line of defense?" Infection and Immunity, vol. 74, no. 10, pp. 5425-5432, 2006.

[113] N. Senhaji, K. Kojok, Y. Darif, C. Fadainia, and Y. Zaid, "The contribution of CD40/CD40L axis in inflammatory bowel disease: an update," Frontiers in Immunology, vol. 6, p. 529, 2015.

[114] K. L. Wallace, L. B. Zheng, Y. Kanazawa, and D. Q. Shih, "Immunopathology of inflammatory bowel disease," World Journal of Gastroenterology, vol. 20, no. 1, pp. 6-21, 2014.

[115] J. T. Lu, A. T. Xu, J. Shen, and Z. H. Ran, "Crosstalk between intestinal epithelial cell and adaptive immune cell in intestinal mucosal immunity," Journal of Gastroenterology and Hepatology, vol. 32, 2017. 
[116] R. J. Xavier and D. K. Podolsky, "Unravelling the pathogenesis of inflammatory bowel disease," Nature, vol. 448, no. 7152, pp. 427-434, 2007.

[117] D. C. Baumgart and W. J. Sandborn, “Crohn's disease," Lancet, vol. 380, no. 9853, pp. 1590-1605, 2012.

[118] F. Biasi, G. Leonarduzzi, P. I. Oteiza, and G. Poli, "Inflammatory bowel disease: mechanisms, redox considerations, and therapeutic targets," Antioxidants \& Redox Signaling, vol. 19, no. 14, pp. 1711-1747, 2013.

[119] G. Rogler, K. Brand, D. Vogl et al., "Nuclear factor kappaB is activated in macrophages and epithelial cells of inflamed intestinal mucosa," Gastroenterology, vol. 115, no. 2, pp. 357-369, 1998.

[120] R. Ungaro, S. Mehandru, P. B. Allen, L. Peyrin-Biroulet, and J. F. Colombel, "Ulcerative colitis," Lancet, vol. 389, 2016.

[121] F. Heller, P. Florian, C. Bojarski et al., "Interleukin-13 is the key effector Th2 cytokine in ulcerative colitis that affects epithelial tight junctions, apoptosis, and cell restitution," Gastroenterology, vol. 129, no. 2, pp. 550-564, 2005.

[122] P. Pacher, J. S. Beckman, and L. Liaudet, "Nitric oxide and peroxynitrite in health and disease," Physiological Reviews, vol. 87, no. 1, pp. 315-424, 2007.

[123] C. G. Knutson, A. Mangerich, Y. Zeng et al., "Chemical and cytokine features of innate immunity characterize serum and tissue profiles in inflammatory bowel disease," Proceedings of the National Academy of Sciences of the United States of America, vol. 110, no. 26, pp. E2332E2341, 2013.

[124] C. F. Babbs, "Oxygen radicals in ulcerative colitis," Free Radical Biology \& Medicine, vol. 13, no. 2, pp. 169-181, 1992.

[125] S. Muthupalani, Z. Ge, Y. Feng et al., "Systemic macrophage depletion inhibits Helicobacter bilis-induced proinflammatory cytokine-mediated typhlocolitis and impairs bacterial colonization dynamics in a BALB/c Rag2-/- mouse model of inflammatory bowel disease," Infection and Immunity, vol. 80, no. 12, pp. 4388-4397, 2012.

[126] T. Kelder, J. H. Stroeve, S. Bijlsma, M. Radonjic, and G. Roeselers, "Correlation network analysis reveals relationships between diet-induced changes in human gut microbiota and metabolic health," Nutrition \& Diabetes, vol. 4, article e122, 2014.

[127] S. Falcinelli, A. Rodiles, S. Unniappan et al., "Probiotic treatment reduces appetite and glucose level in the zebrafish model," Scientific Reports, vol. 6, p. 18061, 2016.

[128] M. Rajilic-Stojanovic, D. M. Jonkers, A. Salonen et al., "Intestinal microbiota and diet in IBS: causes, consequences, or epiphenomena?" The American Journal of Gastroenterology, vol. 110, no. 2, pp. 278-287, 2015.

[129] G. Tomasello, M. Mazzola, A. Leone et al., "Nutrition, oxidative stress and intestinal dysbiosis: influence of diet on gut microbiota in inflammatory bowel diseases," Biomedical Papers of the Medical Faculty of the University Palacky, Olomouc, Czech Republic, vol. 160, no. 4, pp. 461-466, 2016.

[130] T. T. Macdonald and G. Monteleone, "Immunity, inflammation, and allergy in the gut," Science, vol. 307, no. 5717, pp. 1920-1925, 2005.

[131] M. H. Giaffer, C. D. Holdsworth, and B. I. Duerden, "Virulence properties of Escherichia coli strains isolated from patients with inflammatory bowel disease," Gut, vol. 33, no. 5, pp. 646-650, 1992.
[132] C. N. Bernstein and F. Shanahan, "Disorders of a modern lifestyle: reconciling the epidemiology of inflammatory bowel diseases," Gut, vol. 57, no. 9, pp. 1185-1191, 2008.

[133] R. J. Chiodini, H. J. Van Kruiningen, W. R. Thayer, R. S. Mer$\mathrm{kal}$, and J. A. Coutu, "Possible role of mycobacteria in inflammatory bowel disease. I. An unclassified Mycobacterium species isolated from patients with Crohn's disease," Digestive Diseases and Sciences, vol. 29, no. 12, pp. 1073-1079, 1984.

[134] E. Liverani, E. Scaioli, C. Cardamone, P. Dal Monte, and A. Belluzzi, "Mycobacterium avium subspecies paratuberculosis in the etiology of Crohn's disease, cause or epiphenomenon?" World Journal of Gastroenterology, vol. 20, no. 36, pp. 1306013070, 2014.

[135] G. P. Donaldson, S. M. Lee, and S. K. Mazmanian, "Gut biogeography of the bacterial microbiota," Nature Reviews. Microbiology, vol. 14, no. 1, pp. 20-32, 2016.

[136] L. Sun, G. M. Nava, and T. S. Stappenbeck, "Host genetic susceptibility, dysbiosis, and viral triggers in inflammatory bowel disease," Current Opinion in Gastroenterology, vol. 27, no. 4, pp. 321-327, 2011.

[137] E. K. Wright, M. A. Kamm, S. M. Teo, M. Inouye, J. Wagner, and C. D. Kirkwood, "Recent advances in characterizing the gastrointestinal microbiome in Crohn's disease: a systematic review," Inflammatory Bowel Diseases, vol. 21, no. 6, pp. 1219-1228, 2015.

[138] T. Irrazabal, A. Belcheva, S. E. Girardin, A. Martin, and D. J. Philpott, "The multifaceted role of the intestinal microbiota in colon cancer," Molecular Cell, vol. 54, no. 2, pp. 309-320, 2014.

[139] D. Collins, A. M. Hogan, and D. C. Winter, "Microbial and viral pathogens in colorectal cancer," The Lancet Oncology, vol. 12, no. 5, pp. 504-512, 2011.

[140] J. P. Nougayrede, S. Homburg, F. Taieb et al., "Escherichia coli induces DNA double-strand breaks in eukaryotic cells," Science, vol. 313, no. 5788, pp. 848-851, 2006.

[141] O. Handa, Y. Naito, and T. Yoshikawa, "Helicobacter pylori: a ROS-inducing bacterial species in the stomach," Inflammation Research, vol. 59, no. 12, pp. 997-1003, 2010.

[142] J. O. Lundberg, E. Weitzberg, J. A. Cole, and N. Benjamin, "Nitrate, bacteria and human health," Nature Reviews. Microbiology, vol. 2, no. 7, pp. 593-602, 2004.

[143] O. D. Maddocks, K. M. Scanlon, and M. S. Donnenberg, “An Escherichia coli effector protein promotes host mutation via depletion of DNA mismatch repair proteins," MBio, vol. 4, no. 3, article e00152-13, 2013.

[144] O. D. Maddocks, A. J. Short, M. S. Donnenberg, S. Bader, and D. J. Harrison, "Attaching and effacing Escherichia coli downregulate DNA mismatch repair protein in vitro and are associated with colorectal adenocarcinomas in humans," PloS One, vol. 4, no. 5, article e5517, 2009.

[145] S. Danese, M. Sans, and C. Fiocchi, "Inflammatory bowel disease: the role of environmental factors," Autoimmunity Reviews, vol. 3, no. 5, pp. 394-400, 2004.

[146] H. S. de Souza and C. Fiocchi, "Immunopathogenesis of IBD: current state of the art," Nature Reviews. Gastroenterology \& Hepatology, vol. 13, no. 1, pp. 13-27, 2016.

[147] C. Manichanh, N. Borruel, F. Casellas, and F. Guarner, "The gut microbiota in IBD," Nature Reviews. Gastroenterology \& Hepatology, vol. 9, no. 10, pp. 599-608, 2012.

[148] M. D. Silverstein, B. A. Lashner, S. B. Hanauer, A. A. Evans, and J. B. Kirsner, "Cigarette smoking in Crohn's disease," 
The American Journal of Gastroenterology, vol. 84, no. 1, pp. 31-33, 1989.

[149] H. Mehta, K. Nazzal, and R. T. Sadikot, "Cigarette smoking and innate immunity," Inflammation Research, vol. 57, no. 11, pp. 497-503, 2008.

[150] H. Wang, M. Yu, M. Ochani et al., "Nicotinic acetylcholine receptor alpha7 subunit is an essential regulator of inflammation," Nature, vol. 421, no. 6921, pp. 384-388, 2003.

[151] R. Eliakim, F. Karmeli, P. Cohen, S. N. Heyman, and D. Rachmilewitz, "Dual effect of chronic nicotine administration: augmentation of jejunitis and amelioration of colitis induced by iodoacetamide in rats," International Journal of Colorectal Disease, vol. 16, no. 1, pp. 14-21, 2001.

[152] X. Guo, J. K. Ko, Q. B. Mei, and C. H. Cho, "Aggravating effect of cigarette smoke exposure on experimental colitis is associated with leukotriene $\mathrm{B}(4)$ and reactive oxygen metabolites," Digestion, vol. 63, no. 3, pp. 180-187, 2001.

[153] X. Guo, W. P. Wang, J. K. Ko, and C. H. Cho, "Involvement of neutrophils and free radicals in the potentiating effects of passive cigarette smoking on inflammatory bowel disease in rats," Gastroenterology, vol. 117, no. 4, pp. 884-892, 1999.

[154] M. I. Covas, P. Gambert, M. Fito, and R. de la Torre, "Wine and oxidative stress: up-to-date evidence of the effects of moderate wine consumption on oxidative damage in humans," Atherosclerosis, vol. 208, no. 2, pp. 297-304, 2010.

[155] I. Rahman, S. K. Biswas, and P. A. Kirkham, "Regulation of inflammation and redox signaling by dietary polyphenols," Biochemical Pharmacology, vol. 72, no. 11, pp. 1439-1452, 2006.

[156] F. Biasi, M. Astegiano, M. Maina, G. Leonarduzzi, and G. Poli, "Polyphenol supplementation as a complementary medicinal approach to treating inflammatory bowel disease," Current Medicinal Chemistry, vol. 18, no. 31, pp. 4851-4865, 2011.

[157] E. Stermer, "Alcohol consumption and the gastrointestinal tract," The Israel Medical Association Journal, vol. 4, no. 3, pp. 200-202, 2002.

[158] S. Siegmund, R. Spanagel, and M. V. Singer, "Role of the brain-gut axis in alcohol-related gastrointestinal diseases-what can we learn from new animal models?" Journal of Physiology and Pharmacology, vol. 54, Supplement 4, pp. 191-207, 2003.

[159] L. Andresen, V. L. Jorgensen, A. Perner, A. Hansen, J. EugenOlsen, and J. Rask-Madsen, "Activation of nuclear factor kap$\mathrm{paB}$ in colonic mucosa from patients with collagenous and ulcerative colitis," Gut, vol. 54, no. 4, pp. 503-509, 2005.

[160] A. Visekruna, T. Joeris, D. Seidel et al., "Proteasome-mediated degradation of IkappaBalpha and processing of p105 in Crohn disease and ulcerative colitis," The Journal of Clinical Investigation, vol. 116, no. 12, pp. 3195-3203, 2006.

[161] M. Pasparakis, "IKK/NF-kappaB signaling in intestinal epithelial cells controls immune homeostasis in the gut," Mucosal Immunology, vol. 1, Supplement 1, pp. S54-S57, 2008.

[162] Y. Kuwano, K. Tominaga, T. Kawahara et al., "Tumor necrosis factor alpha activates transcription of the NADPH oxidase organizer 1 (NOXO1) gene and upregulates superoxide production in colon epithelial cells," Free Radical Biology \& Medicine, vol. 45, no. 12, pp. 1642-1652, 2008.

[163] W. Jeong, Y. Jung, H. Kim, S. J. Park, and S. G. Rhee, “Thioredoxin-related protein 14 , a new member of the thioredoxin family with disulfide reductase activity: implication in the redox regulation of TNF-alpha signaling," Free Radical Biology \& Medicine, vol. 47, no. 9, pp. 1294-1303, 2009.

[164] Y. Naito, T. Takagi, T. Ishikawa et al., "Alpha-phenyl-N-tertbutylnitrone provides protection from dextran sulfate sodium-induced colitis in mice," Antioxidants \& Redox Signaling, vol. 4, no. 1, pp. 195-206, 2002.

[165] W. Qiu, B. Wu, X. Wang et al., "PUMA-mediated intestinal epithelial apoptosis contributes to ulcerative colitis in humans and mice," The Journal of Clinical Investigation, vol. 121 , no. 5, pp. 1722-1732, 2011.

[166] T. O. Khor, M. T. Huang, K. H. Kwon, J. Y. Chan, B. S. Reddy, and A. N. Kong, "Nrf2-deficient mice have an increased susceptibility to dextran sulfate sodium-induced colitis," Cancer Research, vol. 66, no. 24, pp. 11580-11584, 2006.

[167] T. O. Khor, M. T. Huang, A. Prawan et al., "Increased susceptibility of Nrf2 knockout mice to colitis-associated colorectal cancer," Cancer Prevention Research (Philadelphia, Pa.), vol. 1, no. 3, pp. 187-191, 2008.

[168] I. Stachel, C. Geismann, K. Aden et al., "Modulation of nuclear factor E2-related factor-2 (Nrf2) activation by the stress response gene immediate early response-3 (IER3) in colonic epithelial cells: a novel mechanism of cellular adaption to inflammatory stress," The Journal of Biological Chemistry, vol. 289, no. 4, pp. 1917-1929, 2014.

[169] X. Kong, R. Thimmulappa, P. Kombairaju, and S. Biswal, "NADPH oxidase-dependent reactive oxygen species mediate amplified TLR4 signaling and sepsis-induced mortality in Nrf2-deficient mice," Journal of Immunology, vol. 185, no. 1, pp. 569-577, 2010.

[170] F. Biasi, C. Mascia, M. Astegiano et al., "Pro-oxidant and proapoptotic effects of cholesterol oxidation products on human colonic epithelial cells: a potential mechanism of inflammatory bowel disease progression," Free Radical Biology \& Medicine, vol. 47, no. 12, pp. 1731-1741, 2009.

[171] C. Mascia, M. Maina, E. Chiarpotto, G. Leonarduzzi, G. Poli, and F. Biasi, "Proinflammatory effect of cholesterol and its oxidation products on CaCo-2 human enterocyte-like cells: effective protection by epigallocatechin-3-gallate," Free Radical Biology \& Medicine, vol. 49, no. 12, pp. 2049-2057, 2010.

[172] L. Kruidenier, I. Kuiper, W. Van Duijn et al., "Imbalanced secondary mucosal antioxidant response in inflammatory bowel disease," The Journal of Pathology, vol. 201, no. 1, pp. 17-27, 2003.

[173] L. Kruidenier, M. E. van Meeteren, I. Kuiper et al., "Attenuated mild colonic inflammation and improved survival from severe DSS-colitis of transgenic Cu/Zn-SOD mice," Free Radical Biology \& Medicine, vol. 34, no. 6, pp. 753-765, 2003.

[174] F. F. Chu, R. S. Esworthy, P. G. Chu et al., "Bacteria-induced intestinal cancer in mice with disrupted Gpx1 and Gpx2 genes," Cancer Research, vol. 64, no. 3, pp. 962-968, 2004.

[175] R. S. Esworthy, B. W. Kim, J. Chow, B. Shen, J. H. Doroshow, and F. F. Chu, "Nox1 causes ileocolitis in mice deficient in glutathione peroxidase-1 and -2," Free Radical Biology \& Medicine, vol. 68, pp. 315-325, 2014.

[176] A. Banning, S. Florian, S. Deubel et al., "GPx2 counteracts PGE2 production by dampening COX-2 and mPGES-1 expression in human colon cancer cells," Antioxidants \& Redox Signaling, vol. 10, no. 9, pp. 1491-1500, 2008.

[177] M. Nishikawa, N. Oshitani, T. Matsumoto, T. Nishigami, T. Arakawa, and M. Inoue, "Accumulation of mitochondrial DNA mutation with colorectal carcinogenesis in 
ulcerative colitis," British Journal of Cancer, vol. 93, no. 3, pp. 331-337, 2005.

[178] A. Dashdorj, K. R. Jyothi, S. Lim et al., "Mitochondriatargeted antioxidant MitoQ ameliorates experimental mouse colitis by suppressing NLRP3 inflammasomemediated inflammatory cytokines," BMC Medicine, vol. 11, p. 178, 2013.

[179] Y. J. Lee, S. Y. Jeong, M. Karbowski, C. L. Smith, and R. J. Youle, "Roles of the mammalian mitochondrial fission and fusion mediators Fis1, Drp1, and Opa1 in apoptosis," Molecular Biology of the Cell, vol. 15, no. 11, pp. 5001-5011, 2004.

[180] A. Piechota-Polanczyk and J. Fichna, "Review article: the role of oxidative stress in pathogenesis and treatment of inflammatory bowel diseases," Naunyn-Schmiedeberg's Archives of Pharmacology, vol. 387, no. 7, pp. 605-620, 2014.

[181] L. Chouchana, C. Narjoz, P. Beaune, M. A. Loriot, and $\mathrm{X}$. Roblin, "Review article: the benefits of pharmacogenetics for improving thiopurine therapy in inflammatory bowel disease," Alimentary Pharmacology \& Therapeutics, vol. 35, no. 1, pp. 15-36, 2012.

[182] K. J. Khan, M. C. Dubinsky, A. C. Ford, T. A. Ullman, N. J. Talley, and P. Moayyedi, "Efficacy of immunosuppressive therapy for inflammatory bowel disease: a systematic review and meta-analysis," The American Journal of Gastroenterology, vol. 106, no. 4, pp. 630-642, 2011.

[183] N. Kannan and C. Guruvayoorappan, "Protective effect of Bauhinia tomentosa on acetic acid induced ulcerative colitis by regulating antioxidant and inflammatory mediators," International Immunopharmacology, vol. 16, no. 1, pp. 5766, 2013.

[184] H. Yanai, N. Salomon, and A. Lahat, "Complementary therapies in inflammatory bowel diseases," Current Gastroenterology Reports, vol. 18, no. 12, p. 62, 2016.

[185] P. P. Trivedi and G. B. Jena, "Melatonin reduces ulcerative colitis-associated local and systemic damage in mice: investigation on possible mechanisms," Digestive Diseases and Sciences, vol. 58, no. 12, pp. 3460-3474, 2013.

[186] L. J. Marnett, "The COXIB experience: a look in the rearview mirror," Annual Review of Pharmacology and Toxicology, vol. 49, pp. 265-290, 2009.

[187] H. H. Arab, M. Y. Al-Shorbagy, D. M. Abdallah, and N. N. Nassar, "Telmisartan attenuates colon inflammation, oxidative perturbations and apoptosis in a rat model of experimental inflammatory bowel disease," Plos One, vol. 9, no. 5, article e97193, 2014.

[188] R. A. Maheshwari, R. Balaraman, G. U. Sailor, and D. B. Sen, "Protective effect of simvastatin and rosuvastatin on trinitrobenzene sulfonic acid-induced colitis in rats," Indian Journal of Pharmacology, vol. 47, no. 1, pp. 17-21, 2015.

[189] P. D. Terry, F. Villinger, G. A. Bubenik, and S. V. Sitaraman, "Melatonin and ulcerative colitis: evidence, biological mechanisms, and future research," Inflammatory Bowel Diseases, vol. 15, no. 1, pp. 134-140, 2009.

[190] G. Paradies, G. Petrosillo, V. Paradies, R. J. Reiter, and F. M. Ruggiero, "Melatonin, cardiolipin and mitochondrial bioenergetics in health and disease," Journal of Pineal Research, vol. 48, no. 4, pp. 297-310, 2010.

[191] M. I. Pablos, M. T. Agapito, R. Gutierrez et al., "Melatonin stimulates the activity of the detoxifying enzyme glutathione peroxidase in several tissues of chicks," Journal of Pineal Research, vol. 19, no. 3, pp. 111-115, 1995.
[192] C. Rodriguez, J. C. Mayo, R. M. Sainz et al., "Regulation of antioxidant enzymes: a significant role for melatonin," Journal of Pineal Research, vol. 36, no. 1, pp. 1-9, 2004.

[193] G. Jena and P. P. Trivedi, "A review of the use of melatonin in ulcerative colitis: experimental evidence and new approaches," Inflammatory Bowel Diseases, vol. 20, no. 3, pp. 553-563, 2014.

[194] V. Motilva, S. Garcia-Maurino, E. Talero, and M. Illanes, "New paradigms in chronic intestinal inflammation and colon cancer: role of melatonin," Journal of Pineal Research, vol. 51, no. 1, pp. 44-60, 2011.

[195] C. Chojnacki, M. Wisniewska-Jarosinska, E. WaleckaKapica, G. Klupinska, J. Jaworek, and J. Chojnacki, "Evaluation of melatonin effectiveness in the adjuvant treatment of ulcerative colitis," Journal of Physiology and Pharmacology, vol. 62, no. 3, pp. 327-334, 2011.

[196] A. Siddiqui, H. Ancha, D. Tedesco, S. Lightfoot, C. A. Stewart, and R. F. Harty, "Antioxidant therapy with $\mathrm{N}$-acetylcysteine plus mesalamine accelerates mucosal healing in a rodent model of colitis," Digestive Diseases and Sciences, vol. 51, no. 4, pp. 698-705, 2006.

[197] L. G. Guijarro, J. Mate, J. P. Gisbert et al., "N-acetyl-L-cysteine combined with mesalamine in the treatment of ulcerative colitis: randomized, placebo-controlled pilot study," World Journal of Gastroenterology, vol. 14, no. 18, pp. 2851-2857, 2008.

[198] S. Kasperczyk, M. Dobrakowski, A. Kasperczyk, G. Machnik, and E. Birkner, "Effect of N-acetylcysteine administration on the expression and activities of antioxidant enzymes and the malondialdehyde level in the blood of lead-exposed workers," Environmental Toxicology and Pharmacology, vol. 37, no. 2, pp. 638-647, 2014.

[199] J. J. Haddad, "Antioxidant and prooxidant mechanisms in the regulation of redox(y)-sensitive transcription factors," Cellular Signalling, vol. 14, no. 11, pp. 879-897, 2002.

[200] I. Amrouche-Mekkioui and B. Djerdjouri, "N-acetylcysteine improves redox status, mitochondrial dysfunction, mucindepleted crypts and epithelial hyperplasia in dextran sulfate sodium-induced oxidative colitis in mice," European Journal of Pharmacology, vol. 691, no. 1-3, pp. 209-217, 2012.

[201] A. S. Porfire, S. E. Leucuta, B. Kiss, F. Loghin, and A. E. Pârvu, "Investigation into the role of $\mathrm{Cu} / \mathrm{Zn}$-SOD delivery system on its antioxidant and antiinflammatory activity in rat model of peritonitis," Pharmacological Reports, vol. 66, no. 4, pp. 670-676, 2014.

[202] C. L. Hou, J. Zhang, X. T. Liu, X. F. Zeng, and S. Y. Qiao, "Superoxide dismutase recombinant Lactobacillus fermentum ameliorates intestinal oxidative stress through inhibiting NF-kappaB activation in a trinitrobenzene sulphonic acidinduced colitis mouse model," Journal of Applied Microbiology, vol. 116, no. 6, pp. 1621-1631, 2014.

[203] T. Ishihara, K. Tanaka, Y. Tasaka et al., "Therapeutic effect of lecithinized superoxide dismutase against colitis," The Journal of Pharmacology and Experimental Therapeutics, vol. 328, no. 1, pp. 152-164, 2009.

[204] Y. Suzuki, T. Matsumoto, S. Okamoto, and T. Hibi, "A lecithinized superoxide dismutase (PC-SOD) improves ulcerative colitis," Colorectal Disease, vol. 10, no. 9, pp. 931934, 2008.

[205] T. L. Mikhailova, E. Sishkova, E. Poniewierka et al., "Randomised clinical trial: the efficacy and safety of propionyl-Lcarnitine therapy in patients with ulcerative colitis receiving 
stable oral treatment," Alimentary Pharmacology \& Therapeutics, vol. 34, no. 9, pp. 1088-1097, 2011.

[206] M. G. Scioli, M. A. Stasi, D. Passeri et al., "Propionyl-L-carnitine is efficacious in ulcerative colitis through its action on the immune function and microvasculature," Clinical and Translational Gastroenterology, vol. 5, article e55, 2014.

[207] B. Romier, Y. J. Schneider, Y. Larondelle, and A. During, "Dietary polyphenols can modulate the intestinal inflammatory response," Nutrition Reviews, vol. 67, no. 7, pp. 363$378,2009$.

[208] A. Kaulmann and T. Bohn, "Bioactivity of polyphenols: preventive and adjuvant strategies toward reducing inflammatory bowel diseases-promises, perspectives, and pitfalls," Oxidative Medicine and Cellular Longevity, vol. 2016, Article ID 9346470, 2016.

[209] M. Chiba, T. Abe, H. Tsuda, H. Tozawa, K. Fujiwara, and H. Imai, "Lifestyle-related disease in Crohn's disease: relapse prevention by a semi-vegetarian diet," World Journal of Gastroenterology, vol. 16, no. 20, pp. 2484-2495, 2010.

[210] T. Vezza, A. Rodriguez-Nogales, F. Algieri, M. P. Utrilla, M. E. Rodriguez-Cabezas, and J. Galvez, "Flavonoids in inflammatory bowel disease: a review," Nutrients, vol. 8, no. 4, p. 211, 2016.

[211] H. R. Sodagari, M. H. Farzaei, R. Bahramsoltani, A. H. Abdolghaffari, M. Mahmoudi, and N. Rezaei, "Dietary anthocyanins as a complementary medicinal approach for management of inflammatory bowel disease," Expert Review of Gastroenterology \& Hepatology, vol. 9, no. 6, pp. 807-820, 2015.

[212] J. Epstein, I. R. Sanderson, and T. T. Macdonald, "Curcumin as a therapeutic agent: the evidence from in vitro, animal and human studies," The British Journal of Nutrition, vol. 103, no. 11, pp. 1545-1557, 2010.

[213] Y. He, Y. Yue, X. Zheng, K. Zhang, S. Chen, and Z. Du, "Curcumin, inflammation, and chronic diseases: how are they linked?" Molecules, vol. 20, no. 5, pp. 9183-9213, 2015.

[214] A. Anthwal, B. K. Thakur, M. S. Rawat, D. S. Rawat, A. K. Tyagi, and B. B. Aggarwal, "Synthesis, characterization and in vitro anticancer activity of C-5 curcumin analogues with potential to inhibit TNF-alpha-induced NF-kappaB activation," BioMed Research International, vol. 2014, Article ID 524161, 2014.

[215] N. S. Chang, N. Joki, J. Mattison, T. Dinh, and S. John, "Characterization of serum adhesive proteins that block tumor necrosis factor-mediated cell death," Cell Death and Differentiation, vol. 4, no. 8, pp. 779-786, 1997.

[216] S. C. Gupta, A. K. Tyagi, P. Deshmukh-Taskar, M. Hinojosa, S. Prasad, and B. B. Aggarwal, "Downregulation of tumor necrosis factor and other proinflammatory biomarkers by polyphenols," Archives of Biochemistry and Biophysics, vol. 559, pp. 91-99, 2014.

[217] Y. Topcu-Tarladacalisir, M. Akpolat, Y. H. Uz et al., "Effects of curcumin on apoptosis and oxidoinflammatory regulation in a rat model of acetic acid-induced colitis: the roles of c-Jun $\mathrm{N}$-terminal kinase and p38 mitogen-activated protein kinase," Journal of Medicinal Food, vol. 16, no. 4, pp. 296305, 2013.

[218] R. A. Taylor and M. C. Leonard, "Curcumin for inflammatory bowel disease: a review of human studies," Alternative Medicine Review, vol. 16, no. 2, pp. 152-156, 2011.
[219] M. S. Baliga, N. Joseph, M. V. Venkataranganna, A. Saxena, V. Ponemone, and R. Fayad, "Curcumin, an active component of turmeric in the prevention and treatment of ulcerative colitis: preclinical and clinical observations," Food \& Function, vol. 3, no. 11, pp. 1109-1117, 2012.

[220] H. Hanai, T. Iida, K. Takeuchi et al., "Curcumin maintenance therapy for ulcerative colitis: randomized, multicenter, double-blind, placebo-controlled trial," Clinical Gastroenterology and Hepatology, vol. 4, no. 12, pp. 1502-1506, 2006.

[221] K. Sugimoto, H. Hanai, K. Tozawa et al., "Curcumin prevents and ameliorates trinitrobenzene sulfonic acidinduced colitis in mice," Gastroenterology, vol. 123, no. 6, pp. 1912-1922, 2002.

[222] J. K. Triantafillidis, A. Triantafyllidi, C. Vagianos, and A. Papalois, "Favorable results from the use of herbal and plant products in inflammatory bowel disease: evidence from experimental animal studies," Annals of Gastroenterology, vol. 29 , no. 3, pp. 268-281, 2016.

[223] N. Schweigert, A. J. Zehnder, and R. I. Eggen, "Chemical properties of catechols and their molecular modes of toxic action in cells, from microorganisms to mammals," Environmental Microbiology, vol. 3, no. 2, pp. 81-91, 2001.

[224] M. J. Carter, A. J. Lobo, and S. P. Travis, "Guidelines for the management of inflammatory bowel disease in adults," Gut, vol. 53, Supplement 5, pp. V1-16, 2004.

[225] A. Kornbluth, D. B. Sachar, and Practice Parameters Committee of the American College of Gastroenterology, "Ulcerative colitis practice guidelines in adults: American College Of Gastroenterology, Practice Parameters Committee," The American Journal of Gastroenterology, vol. 105, no. 3, pp. 501-523, 2010, quiz 524.

[226] H. H. Arab, S. A. Salama, A. H. Eid, H. A. Omar, E. S. Arafa, and I. A. Maghrabi, "Camel's milk ameliorates TNBSinduced colitis in rats via downregulation of inflammatory cytokines and oxidative stress," Food and Chemical Toxicology, vol. 69, pp. 294-302, 2014.

[227] M. J. Oliveras-Lopez, G. Berna, E. M. Carneiro, H. L. de la Serrana, F. Martín, and M. C. López, "An extra-virgin olive oil rich in polyphenolic compounds has antioxidant effects in OF1 mice," The Journal of Nutrition, vol. 138, no. 6, pp. 1074-1078, 2008.

[228] R. W. Owen, R. Haubner, G. Wurtele, W. E. Hull, B. Spiegelhalder, and H. Bartsch, "Olives and olive oil in cancer prevention," European Journal of Cancer Prevention, vol. 13, no. 4, pp. 319-326, 2004.

[229] M. Bitiren, A. Z. Karakilcik, M. Zerin et al., "Protective effects of selenium and vitamin $\mathrm{E}$ combination on experimental colitis in blood plasma and colon of rats," Biological Trace Element Research, vol. 136, no. 1, pp. 87-95, 2010.

[230] N. D'Orazio, M. A. Gammone, E. Gemello, M. De Girolamo, S. Cusenza, and G. Riccioni, "Marine bioactives: pharmacological properties and potential applications against inflammatory diseases," Marine Drugs, vol. 10, no. 4, pp. 812-833, 2012.

[231] C. W. Barrett, S. P. Short, and C. S. Williams, "Selenoproteins and oxidative stress-induced inflammatory tumorigenesis in the gut," Cellular and Molecular Life Sciences, vol. 74, 2016.

[232] C. W. Barrett, K. Singh, A. K. Motley et al., "Dietary selenium deficiency exacerbates DSS-induced epithelial injury and AOM/DSS-induced tumorigenesis," PloS One, vol. 8, no. 7, article e67845, 2013. 
[233] S. M. Barbalho, A. Goulart Rde, K. Quesada, M. D. Bechara, and A. D. de Carvalho, "Inflammatory bowel disease: can omega-3 fatty acids really help?" Annals of Gastroenterology, vol. 29 , no. 1, pp. 37-43, 2016.

[234] H. Zhang, C. A. Hu, J. Kovacs-Nolan, and Y. Mine, "Bioactive dietary peptides and amino acids in inflammatory bowel disease," Amino Acids, vol. 47, no. 10, pp. 2127-2141, 2015.

[235] N. Sengul, S. Isik, B. Aslim, G. Uçar, and A. E. Demirbağ, "The effect of exopolysaccharide-producing probiotic strains on gut oxidative damage in experimental colitis," Digestive Diseases and Sciences, vol. 56, no. 3, pp. 707-714, 2011.

[236] L. Zhong, X. Zhang, and M. Covasa, "Emerging roles of lactic acid bacteria in protection against colorectal cancer," World Journal of Gastroenterology, vol. 20, no. 24, pp. 7878-7886, 2014.

[237] A. Amaretti, M. di Nunzio, A. Pompei, S. Raimondi, M. Rossi, and A. Bordoni, "Antioxidant properties of potentially probiotic bacteria: in vitro and in vivo activities," Applied Microbiology and Biotechnology, vol. 97, no. 2, pp. 809-817, 2013.

[238] E. Songisepp, J. Kals, T. Kullisaar et al., "Evaluation of the functional efficacy of an antioxidative probiotic in healthy volunteers," Nutrition Journal, vol. 4, p. 22, 2005.

[239] D. Haller, J. M. Antoine, S. Bengmark, P. Enck, G. T. Rijkers, and I. Lenoir-Wijnkoop, "Guidance for substantiating the evidence for beneficial effects of probiotics: probiotics in chronic inflammatory bowel disease and the functional disorder irritable bowel syndrome," The Journal of Nutrition, vol. 140, no. 3, pp. 690S-697S, 2010.

[240] D. Jonkers, J. Penders, A. Masclee, and M. Pierik, "Probiotics in the management of inflammatory bowel disease: a systematic review of intervention studies in adult patients," Drugs, vol. 72, no. 6, pp. 803-823, 2012.

[241] K. Biswas, U. Bandyopadhyay, I. Chattopadhyay, A. Varadaraj, E. Ali, and R. K. Banerjee, "A novel antioxidant and antiapoptotic role of omeprazole to block gastric ulcer through scavenging of hydroxyl radical," The Journal of Biological Chemistry, vol. 278, no. 13, pp. 10993-11001, 2003.

[242] M. R. Mazalli and N. Bragagnolo, "Increase of cholesterol oxidation and decrease of PUFA as a result of thermal processing and storage in eggs enriched with n-3 fatty acids," Journal of Agricultural and Food Chemistry, vol. 57, no. 11, pp. 5028-5034, 2009.

[243] D. A. Parks, "Oxygen radicals: mediators of gastrointestinal pathophysiology," Gut, vol. 30, no. 3, pp. 293-298, 1989.

[244] I. S. Young and J. V. Woodside, "Antioxidants in health and disease," Journal of Clinical Pathology, vol. 54, no. 3, pp. 176-186, 2001.

[245] F. Borrelli, I. Fasolino, B. Romano et al., "Beneficial effect of the non-psychotropic plant cannabinoid cannabigerol on experimental inflammatory bowel disease," Biochemical Pharmacology, vol. 85, no. 9, pp. 1306-1316, 2013.

[246] M. Herulf, T. Ljung, P. M. Hellstrom, E. Weitzberg, and J. O. Lundberg, "Increased luminal nitric oxide in inflammatory bowel disease as shown with a novel minimally invasive method," Scandinavian Journal of Gastroenterology, vol. 33, no. 2, pp. 164-169, 1998.

[247] S. J. McKenzie, M. S. Baker, G. D. Buffinton, and W. F. Doe, "Evidence of oxidant-induced injury to epithelial cells during inflammatory bowel disease," The Journal of Clinical Investigation, vol. 98, no. 1, pp. 136-141, 1996.
[248] C. J. Schorah, "Antioxidants in children with inflammatory bowel disease," The American Journal of Clinical Nutrition, vol. 67, no. 1, pp. 151-152, 1998.

[249] B. Sido, V. Hack, A. Hochlehnert, H. Lipps, C. Herfarth, and W. Dröge, "Impairment of intestinal glutathione synthesis in patients with inflammatory bowel disease," Gut, vol. 42, no. 4, pp. 485-492, 1998. 


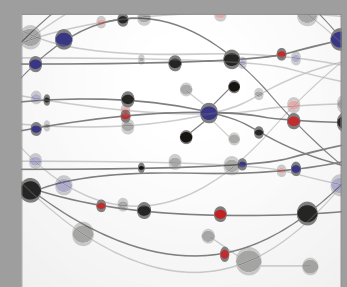

The Scientific World Journal
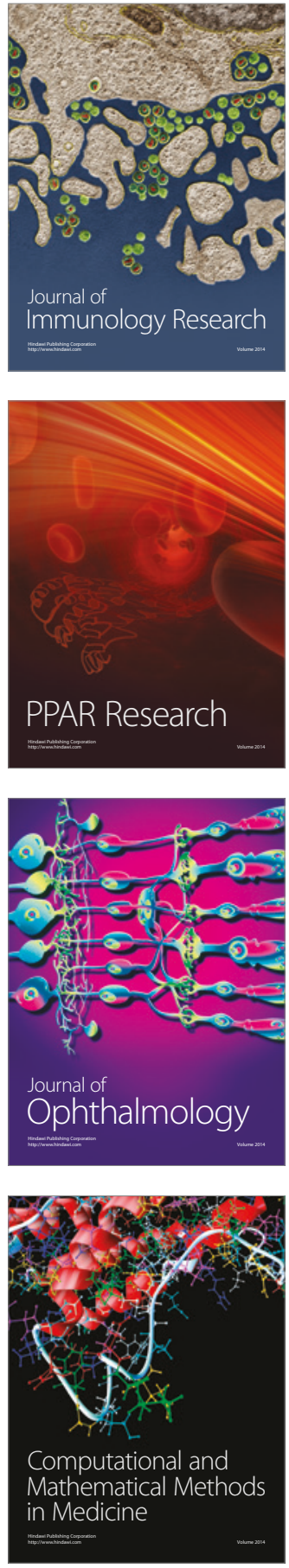

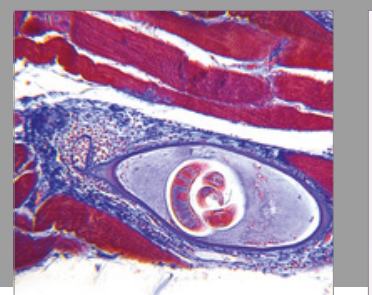

Gastroenterology Research and Practice
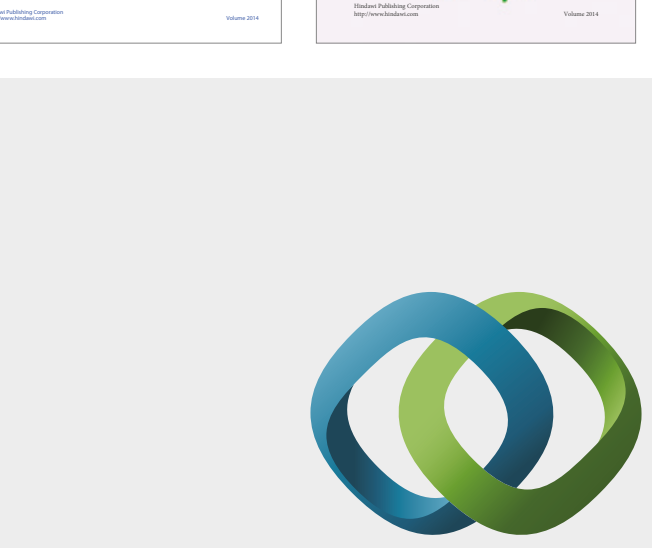

\section{Hindawi}

Submit your manuscripts at

https://www.hindawi.com
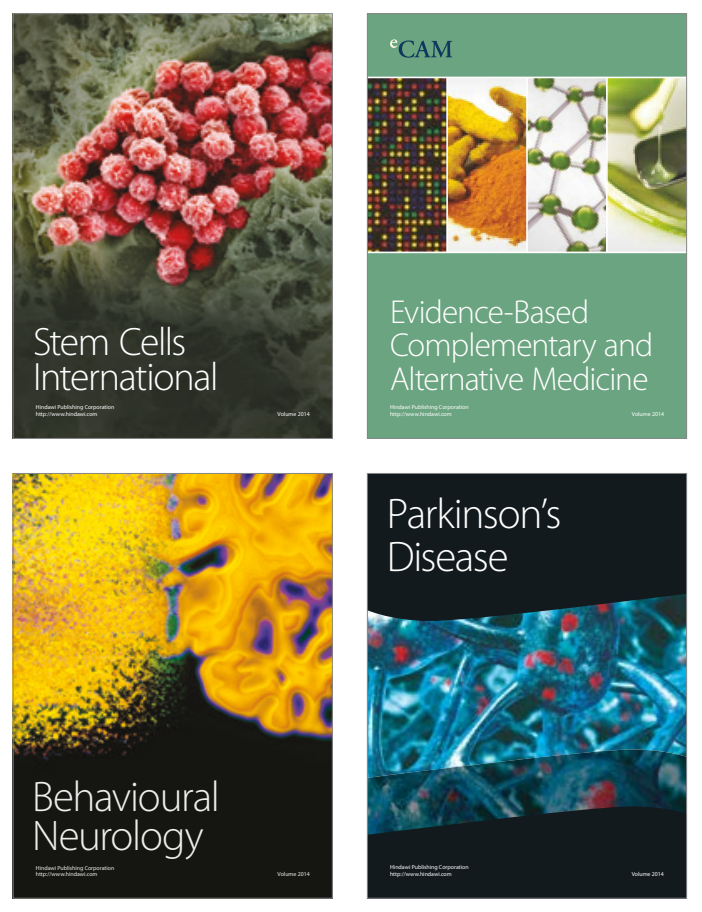
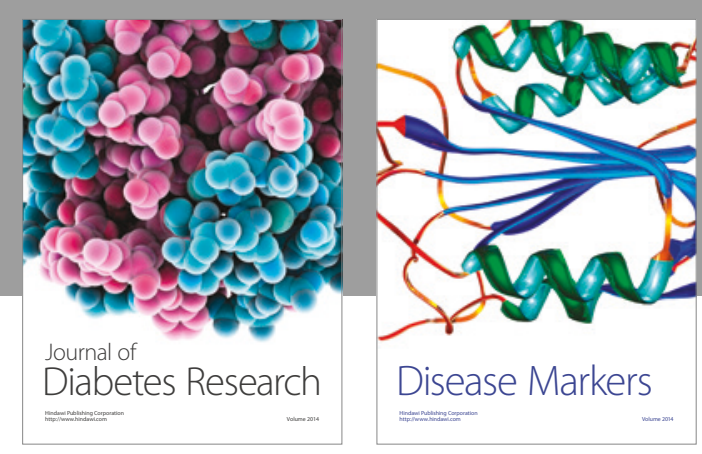

Disease Markers
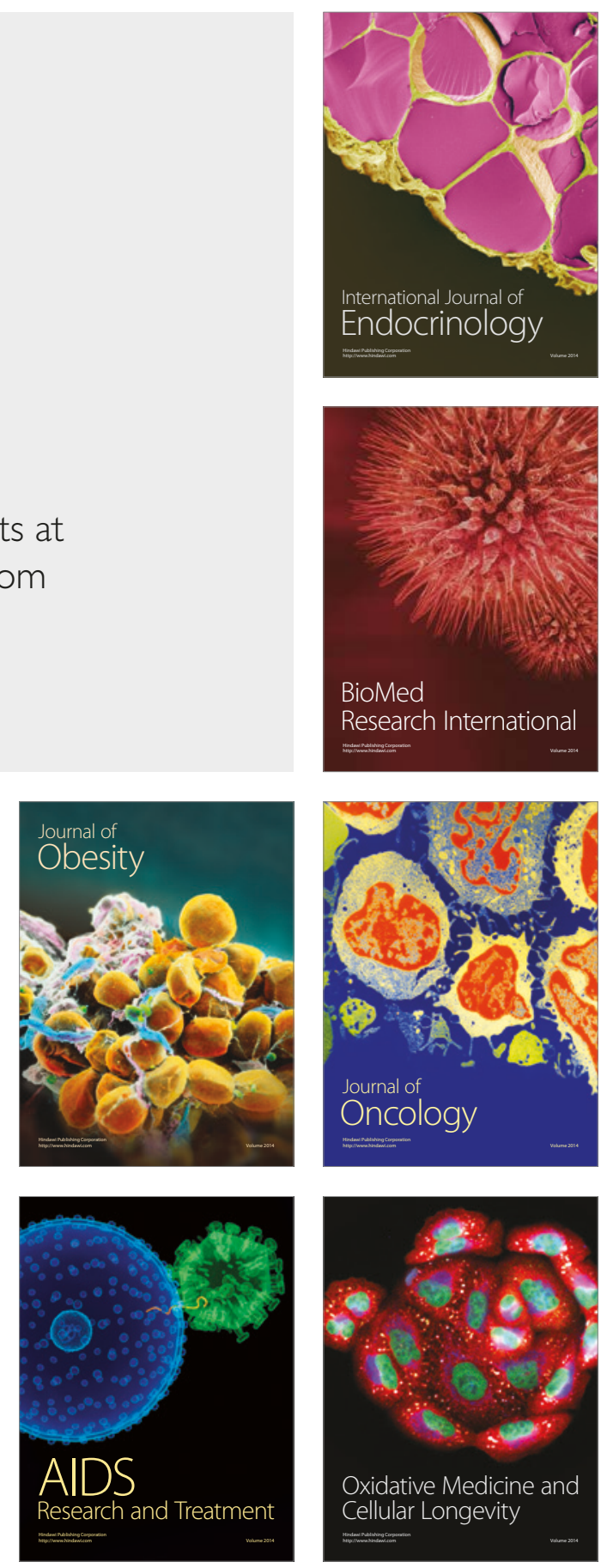